\title{
Caracterização da Pluriatividade e dos Plurirrendimentos da Agricultura Brasileira a partir do Censo Agropecuário 2006
}

\author{
Fabiano Escher ${ }^{1}$, Sergio Schneider ${ }^{2}$, Luciana Maria Scarton ${ }^{3}$ \\ e Marcelo Antonio Conterato ${ }^{4}$
}

Resumo: $\mathrm{O}$ artigo trata do fenômeno da pluriatividade na agricultura brasileira, referente à diversificação das atividades econômicas e laborais exercidas no meio rural, e dos plurirrendimentos, referentes à diversificação das fontes de renda acessadas pelos agricultores e suas famílias. Com base nos dados do Censo Agropecuário 2006, realiza-se uma análise para o Brasil e as regiões Sul e Nordeste do País, buscando comparar os assim denominados "estabelecimentos pluriativos" pertencentes às categorias agricultura familiar e agricultura não familiar. O trabalho identifica e quantifica esses estabelecimentos; caracteriza-os segundo o tipo de pluriatividade e a relação de trabalho do pessoal ocupado; e identifica as suas distintas fontes de receitas, mensurando a importância de cada uma na formação da receita total. A constatação empírica de um percentual maior de estabelecimentos de agricultura não familiar classificados como pluriativos $(51,9 \%)$ do que na própria agricultura familiar $(34,1 \%)$ levou a uma intrigante questão teórica, já que a quase totalidade dos estudos sobre pluriatividade no Brasil sempre considerou o fenômeno como uma especificidade da agricultura familiar. Embora essa questão seja apenas brevemente discutida no artigo, o resultado mais significativo é que deve haver uma importante parcela dos agricultores familiares que, justamente por serem pluriativos, encontram-se inadequadamente classificados como agricultores não familiares e, portanto, excluídos das estatísticas oficiais e, possivelmente, das próprias políticas públicas voltadas à agricultura familiar.

Palavras-chaves: Agricultura familiar, agricultura não familiar, pluriatividade, plurirrendimentos, Censo Agropecuário 2006.

1. Mestre em Desenvolvimento Rural pelo PGDR-UFRGS (Programa de Pós-graduação em Desenvolvimento Rural - Universidade Federal do Rio Grande do Sul) e doutorando em Desenvolvimento Rural pelo PGDR-UFRGS. E-mail: escher_fab@hotmail.com

2. Professor no Departamento de Sociologia e nos Programas de Pós-graduação em Sociologia (PPGS) e Desenvolvimento Rural (PGDR) da UFRGS. É doutor em Sociologia pela UFRGS e mestre em Sociologia pela Unicamp. E-mail: schneide@ufrgs.br

3. É especialista em Marketing pela Unijuí (RS) e mestre em Agronegócio pelo Cepan/UFRGS. É doutoranda em Agronegócio pelo Cepan/UFRGS. E-mail: luscarton@hotmail.com

4. Professor na Faculdade de Ciências Econômicas (FCE) e no Programa de Pós-graduação em Desenvolvimento Rural (PGDR) da UFRGS e mestre e doutor em Desenvolvimento Rural pelo PGDR-UFRGS. E-mail: marcelo.conterato@ufrgs.br 


\begin{abstract}
The article discusses the phenomenon of pluriactivity in Brazilian agriculture, referring to the diversification of economic and labour activities in rural areas, and pluri-incomes, referring to the diversification of income sources accessed by farmers and their families. Based on 2006 Agricultural Census data, an analysis for Brazil and Southern and Northeastern regions of the country is carried out, trying to compare the so-called "pluriactive households" belonging to family farming and non-family farming categories. The paper identifies and quantifies these households; characterize them according to the type of pluriactivity and the labour relations of employed persons; and identifies their distinct revenue sources, measuring the importance of each one in the formation of total revenue. The empirical finding of a higher percentage of non-family farming households classified as pluriactive (51.9\%) than the family farming (34.1\%) led to an intriguing theoretical question, since almost all the studies in Brazil always considered pluriactivity as a phenomenon specific to family farming. Although this question is only briefly discussed, the most significant result is that there must be an important part of family farmers who, precisely because they are pluriactive, are improperly classified as non-family farmers and, therefore, excluded from official statistics and possibly of the very public policies suitable for family farming.
\end{abstract}

Key-words: Family farming, non-family farming, pluriactivity, pluri-incomes, agricultural Census 2006.

Classificação JEL: Q12, R20, Z13.

\section{Introdução}

Nas últimas décadas, especialmente desde a metade dos anos 1990, a agricultura brasileira conheceu mudanças estruturais que estão alterando várias de suas características históricas, socioeconômicas e espaciais. Muitas destas mudanças são ainda insuficientemente compreendidas, descritas e analisadas. Não obstante, promissoras expectativas foram abertas a partir dos dados do Censo Agropecuário de 2006 (CA 2006 daqui em diante), publicados pelo IBGE em 2009. Os estudos em torno do tema da pluriatividade, que envolve também a análise das ocupações agrícolas e não agrícolas, das fontes de renda e receita, das dinâmicas dos mercados de trabalho, das economias locais e do desenvolvimento territorial, bem como da influência destes temas nas políticas públicas, são muito ilustrativos desse estado de ânimo.

Internacionalmente, alguns trabalhos se tornaram referência obrigatória no estudo da pluriatividade, tal como a pesquisa realizada no âmbito do consórcio Arkleton Trust (1992) sobre o caso europeu, onde $63 \%$ das unidades produ- tivas apresentavam algum dos membros da família engajado em atividades não agrícolas ou fora do estabelecimento. Anos mais tarde, o próprio Banco Mundial também produziu estudos e estimulou avaliações sobre a combinação de atividades agrícolas e não-agrícolas e da importância das rendas não agrícolas na redução da pobreza e na melhoria da situação socioeconômica nas áreas rurais, sugerindo abandonar o "estreito foco do setor agrícola" (WORLD BANK, 1997, 2000; BIRD, 2008).

No Brasil, desde os anos 1990 foram desenvolvidas várias pesquisas utilizando dados secundários e primários, as quais permitiram dimensionar e caracterizar a presença e a importância econômica das atividades e rendas não agrícolas entre os agricultores. Entre os trabalhos pioneiros sobre a dupla atividade dos agricultores, ainda na década de 1980, os estudos de Seyferth (1974, 1984, 1987) sobre os "colonos-operários" são a principal referência. Adentrando os anos 1990, as novas pesquisas publicadas (SCHNEIDER, 1994, 1999; ANJOS, 1995; CARNEIRO, 1996; NEVES, 1995, 1997) passaram a incorporar as noções de part-time farming e multiple-job holding, que já 
haviam sido utilizadas na Europa para descrever as situações em que parcela crescente dos agricultores dedica apenas uma parte de sua jornada de trabalho às atividades agrícolas. E no final da década de 1990 os estudos sobre pluriatividade passaram a caracterizar-se pela perspectiva que esta noção adquiriu a partir da definição de Fuller (1990) e Brun e Fuller (1991). Os principais trabalhos sobre pluriatividade dessa fase (CARNEIRO, 1998; KAGEYAMA, 1998; SCHNEIDER, 2003; ANJOS, 2003) concentraram-se na análise da combinação de atividades agrícolas e não agrícolas na agricultura familiar e nos efeitos sobre as economias locais, muitas vezes incorporando o debate sobre a (nova) ruralidade (CARNEIRO, 2001; VEIGA, 2002; WANDERLEY, 2004).

Mas o impulso decisivo ao estudo da pluriatividade no Brasil ocorreu à medida que se ampliaram as pesquisas sobre as mudanças econômicas, espaciais e ocupacionais no mercado de trabalho, especialmente aquelas conduzidas no âmbito do Projeto RURBANO ${ }^{5}$, através do qual se realizou uma nova caracterização da população residente no meio rural brasileiro e do meio rural paulista em particular, tornando-se referência nesse tipo de análise (CampanholA, Graziano da Silva, 2004; Graziano da Silva, 1999). Junto com os trabalhos citados no parágrafo anterior, essas pesquisas geraram diversos relatórios e publicações com informações importantes, que contribuíram para a redefinição de políticas públicas, as quais passaram a considerar essa nova realidade existente no meio rural do país (SCHNEIDER,

5. O projeto Rurbano começou a ser desenvolvido a partir da divulgação pelo IBGE dos microdados das Pesquisas Nacionais por Amostra de Domicílios (PNAD's) e foi composto de três (3) fases. As suas principais conclusões foram as seguintes: Fase I: o emprego agrícola diminuía sistematicamente desde meados dos anos 80 , mas a população rural ocupada crescia no mesmo período; Fase II: revelou a importância da pluriatividade e dos rendimentos não-agrícolas para as famílias rurais, especialmente o papel das transferências de renda na forma de aposentadorias e pensões aos agricultores familiares; Fase IIII: impacto positivo da pluriatividade na renda familiar, mas esta ainda é menor que o impacto das aposentadorias; sua associação a menores índices de pobreza e que a participação do autoconsumo na composição da renda familiar não se revelou elevado.
2007). Inclusive, a partir de junho de 2011, o próprio Programa Nacional de Fortalecimento da Agricultura Familiar (Pronaf), passou a considerar a conjugação das tradicionais atividades agropecuárias e seus respectivos rendimentos com as atividades não agropecuárias e os rendimentos delas provenientes entre os critérios que definem seu público alvo, aumentando, ao menos em tese, a abrangência dos potenciais beneficiários da política. ${ }^{6}$

Apoiados em um sofisticado tratamento dos dados das PNAD's ${ }^{7}$, vários autores fizeram e continuam a fazer grandes avanços analíticos, com estudos sobre as transformações do mercado de trabalho rural e as dinâmicas da pluriatividade no Brasil (SAKAMOTO e MAIA, 2012; LAURENTI, TELLES e PELLINI, 2013) em estados do Sul (SOUZA e NASCIMENTO, 2006; SHURMAN et al., 2010; BAZOTTI, NAZARENO e CINTRA, 2010) e do Nordeste (LIMA e NEDER, 2009; NASCIMENTO e AQUINO, 2010) e inclusive comparando as duas regiões (NASCIMENTO e CARDOZO, 2007). Contudo, são reconhecidos alguns limites dessa base dados para pesquisar o tema da pluriatividade no meio rural (MATTEI, 2007). Por se tratar de uma pesquisa amostral, os dados agregados são apenas estimativas que, apesar de estatisticamente significativas, não tratam de dados reais apurados em todos os domicílios, como no caso dos dados dos

6. “O Ministério da Fazenda permitirá o enquadramento de famílias "com um ou dois membros" cujas atividades "não agrícolas" sejam exercidas fora do estabelecimento rural. Hoje, a lei prevê que a mão de obra empregada na propriedade seja "predominantemente" da própria família. A medida para permitir a chamada "pluriatividade" foi anunciada ontem, em audiência no Senado, pelo secretário-adjunto de Política Econômica da Fazenda, Gilson Bittencourt. A alteração fará parte da reforma do Manual de Crédito Rural (MCR)." Noticia publicado no Jornal Valor Econômico em 10.06.2011.

7. Vale dizer que, de acordo com os dados da PNAD de 2009, haveria naquele ano 8.749 .853 domicílios rurais no Brasil, sendo que $4.253 .466(48,6 \%)$ famílias poderiam ser consideradas não pluriativas e $4.496 .387(51,4 \%)$ pluriativas. Na região Sul seriam ao todo 1.452 .045 domicílios rurais, dos quais $742.765(51,2 \%)$ poderiam ser consideradas de famílias não pluriativas e 709.283 (48,8\%) de famílias pluriativas. E na região Nordeste haveria 3.957.644 domicílios rurais, sendo que $1.657 .414(41,9 \%)$ poderiam ser considerados não pluriativos e $2.300 .230(58,1 \%)$ pluriativos. 
Censos Agropecuários, que levanta dados sobre praticamente todos os estabelecimento agropecuários. A PNAD é uma pesquisa amostral realizada em regiões metropolitanas e não metropolitanas, mas que não alcança todos os municípios, micro e meso regiões. Além do mais, dada a sua natureza de pesquisa domiciliar, apresenta os dados de ocupação dos indivíduos (e não de estabelecimentos ou imóveis), prestando-se mais propriamente à análises da estrutura ocupacional e da dinâmica do mercado de trabalho, e não à estrutura e dinâmica das famílias e suas unidades produção. ${ }^{8}$

Apesar dos avanços nos instrumentos de política pública e nos instrumentos metodológicos, refletidos na existência dessas e outras publicações com diversas informações importantes, ainda persistem lacunas a serem investigadas. Assim, outros tipos de informação sobre as atividades não agrícolas e os contextos que geram ou favorecem o aparecimento da pluriatividade no meio rural brasileiro poderiam ser muito úteis para verificar e compreender não somente a incidência destas atividades, mas também oferecer subsídios para pesquisas futuras em questões teóricas, metodologias empíricas e debates sobre diversos aspectos, bem como para o próprio aprimoramento das políticas públicas de desenvolvimento rural. Nesse sentido, a publicação dos dados do CA 2006 e as inovações por ele trazidas constituem um fato marcante, que vem contribuir para o preenchimento de algumas dessas lacunas ainda existentes nos estudos e pesquisas sobre pluriatividade no Brasil.

8. Na Pesquisa Nacional por Amostra de Domicílios (PNAD) a unidade de referência do levantamento de dados são os domicílios rurais. Não é raro que em um mesmo estabelecimento agropecuário haja mais do que um domicílio ou mesmo que um mesmo domicílio possa ter relação a mais de um estabelecimento agropecuário, pois muitos agricultores residem em um domicílio, mas possuem mais de um estabelecimento (é comum agricultores terem mais de um imóvel rural, pois a unidade de produção pode estar desmembrada em várias partes por razões de herança ou mesmo aquisição). Por tudo isto, não se trata de afirmar que o estabelecimento agropecuário é uma unidade de análise melhor do que o domicílio rural, mas as informações sobre a produção e as atividades realizadas pelos produtores são mais completas no Censo Agropecuário.
De fato, o Censo Agropecuário 2006 abriu novas possibilidades de investigação sobre as características sociológicas e econômicas dos estabelecimentos agropecuários, quando passou a incluir questões que permitem apurar a existência de atividades não agropecuárias ou o exercício de atividades fora do estabelecimento pelos chefes e/ou membros da unidade.

Neste sentido, o objetivo geral desse artigo consiste em apresentar uma caracterização da pluriatividade e dos rendimentos dos produtores e membros das famílias residentes nos estabelecimentos agropecuários do Brasil e das regiões Sul e Nordeste, segundo o corte pelas categorias agricultura familiar e agricultura não familiar. $\mathrm{O}$ trabalho possui ainda três objetivos específicos, a saber: 1) identificar e quantificar os estabelecimentos onde os produtores e/ou algum dos membros das famílias exercem a "pluriatividade econômica"; 2) caracterizar os estabelecimentos onde se identifica o exercício da pluriatividade segundo o tipo de pluriatividade exercida e a relação de trabalho do pessoal ocupado; 3) identificar as distintas fontes de receitas dos estabelecimentos que indicam o exercício de pluriatividade e a diversificação das receitas, mensurando a importância de cada fonte na formação da receita total.

Além dessa breve introdução e das considerações finais, o artigo contém mais três seções. $\mathrm{Na}$ segunda seção, são discutidas as principais características e inovações metodológicas do Censo Agropecuário 2006, definidos os conceitos operacionais e explicitados os procedimentos adotados neste estudo com base nos dados do IBGE. Também são realizados breves apontamentos de ordem conceitual. Na terceira seção, o foco é responder os objetivos específicos 1 e 2 , apresentando os dados da pluriatividade no Brasil e nas regiões Sul e Nordeste. Na quarta seção, o foco é responder ao objetivo específico 3, quando são analisadas as distintas fontes de receitas dos estabelecimentos pluriativos e seus valores percentuais. Por fim, na última seção são apresentadas as considerações finais, contendo as principais conclusões do artigo, pontos para a agenda de pesquisas no tema da pluriatividade e dos plu- 
rirrendimentos com base nos dados do Censo Agropecuário do IBGE, e as potenciais contribuições destes estudos para as políticas públicas de desenvolvimento rural.

\section{Metodologia e definições conceituais}

Os dados utilizados neste trabalho são oriundos do Censo Agropecuário de 2006 (CA 2006), publicado pelo Instituto Brasileiro de Geografia e Estatística (IBGE) em 2009. O nível e as unidades territoriais de análise em tela contêm dados agregados referentes ao Brasil e aos estados das grandes regiões Sul (3) e Nordeste (9). A unidade básica de investigação é o "estabelecimento agropecuário", definido como segue pelo IBGE.

[Estabelecimento agropecuário é toda] unidade de produção dedicada, total ou parcialmente, a atividades agropecuárias, florestais e aquícolas, subordinada a uma única administração: a do produtor ou a do administrador. Independente de seu tamanho, de sua forma jurídica ou de sua localização em área urbana ou rural, tendo como objetivo a produção para subsistência e/ou para venda, constituindo-se assim numa unidade recenseável (IBGE, 2009b, p. 7).

A pesquisa realizada nessa ultima edição do Censo Agropecuário (CA 2006) passou a incorporar conceitos correspondentes a elementos que vem assumindo notoriedade ou às novidades que se integraram ao universo agrícola nacional (IBGE, 2009a). Esse é o caso do que o IBGE (2009a) designou "pluriatividade econômica do produtor e membros de sua família". Contudo, não há nas publicações do CA 2006 uma definição com critérios objetivos para aquilo que se denominará como "estabelecimento pluriativo", principal categoria de análise operacionalizada nesse trabalho. Não obstante, mesmo que metodologicamente a pesquisa tenha contado somente com uma análise tabular simples, acredita-se que foram alcançados resultados interessantes, apesar de ainda parciais, em termos de cruzamento de dados e de identificação, mensuração e caracterização do universo. Assim, define-se como um estabelecimento pluriativo (EP) aquele estabelecimento agropecuário em que o produtor e/ou algum membro da família exerceu atividades agropecuárias e algum tipo de atividade não agropecuária remunerada e/ou qualquer tipo de atividade remunerada fora do estabelecimento. São considerados "estabelecimentos pluriativos", portanto, aqueles estabelecimentos em que apenas o produtor exerceu pluriatividade, os estabelecimentos em que algum membro da família exerceu pluriatividade e aqueles estabelecimentos em que o produtor e algum membro da família exerceram pluriatividade. ${ }^{9}$

A partir da definição desses critérios foi possível aplicar operacionalmente o conceito de pluriatividade para identificar, quantificar e caracterizar o universo dos estabelecimentos pluriativos com base nos dados do Censo Agropecuário 2006 do IBGE $(2009 b, 2009$ c). Para os propósitos desse artigo, basta dizer que trabalha-se com a definição do próprio IBGE, baseada na Lei n. 11.326, no que concerne a distinção entre estabelecimentos agropecuários pertencentes as categorias de agricultura familiar (AF) e de agricultura não familiar (ANF), sem preocupar-se com aspectos teóricos mais gerais sobre a relação entre agricultura familiar, pluriatividade e capitalismo, os quais, apesar da óbvia importância, não serão tratados aqui. ${ }^{10}$

9. Optou-se definir operacionalmente a pluriatividade de um estabelecimento a partir da resposta positiva as perguntas 1 e 2 do Bloco 10 do Questionário aplicado pelos recenseadores, que perguntavam sobre o exercício de alguma atividade remunerada fora do estabelecimento agropecuário, seja por parte do produtor ou de algum membro da família do mesmo. Contudo, essa opção pode, eventualmente, ter levado a certa subestimação do universo dos estabelecimentos pluriativos, pois também poderiam ter sido inseridos nesta categoria aqueles onde algum dos integrantes realizou atividades não agropecuárias dentro do estabelecimento.

10. Essa definição se baseia na Lei n. 11.326, de 24 de julho de 2006, que estabelece as diretrizes para a formulação da Política Nacional da Agricultura Familiar e Empreendimentos Familiares Rurais, com base em quatro critérios: tamanho de área de no máximo quatro módulos fiscais; mão de obra predominantemente familiar; rendimento agrícola do estabelecimento maior do que os salários obtidos fora; e direção do estabelecimento realizado pelos membros da família (IBGE, 2009c). Temos clareza 
Mas antes de adentrar na descrição e análise dos dados estatísticos propriamente ditos, é importante retomar alguns elementos conceituais necessários para a análise do fenômeno da pluriatividade nos estabelecimentos agropecuários. Para fins de definição, assim como é entendida neste trabalho, a pluriatividade que ocorre no meio rural refere-se a um fenômeno que pressupõem a combinação de pelo menos duas atividades, sendo uma delas a agricultura (ou agropecuária). Essas múltiplas atividades são exercidas por indivíduos pertencentes a um grupo doméstico ligado por laços de parentesco e consanguinidade (filiação), podendo pertencê-lo, eventualmente, outros membros não consanguíneos (adoção) que compartilham entre si um mesmo espaço doméstico e produtivo de moradia e trabalho (não necessariamente em um mesmo domicílio, alojamento ou habitação) e se identificam como uma família.

A referência às várias (pluri) atividades, portanto, também requer uma definição. Uma atividade consiste na execução de um conjunto de tarefas, procedimentos e operações de caráter produtivo e laboral, tais como plantio, manejo, colheita, limpeza, preparação, organização, beneficiamento, venda, etc. A atividade agrícola/ agropecuária, ou simplesmente a agricultura, compreende uma miríade diversificada e complexa de tarefas, procedimentos e operações que envolvem o cultivo de organismos vivos (animais

\footnotetext{
do caráter meramente normativo e classificatório dessa definição e distinção $\mathrm{AF} / \mathrm{ANF}$, que possuem várias dificuldades conceituais e, portanto, não devem ser utilizadas com pretensões heurísticas que visam explicar a realidade através de análise propriamente teórica. Os artigos de Guanzirolli, Buainain e Di Sabbatto (2012) e de Kageyama, Bergamasco e Oliveira (2013) avançam neste sentido. Mas mesmo assim acreditamos que essa distinção entre as duas categorias é interessante para os propósitos dessa pesquisa. Primeiro, porque essa é a definição legal e normativa que rege a política pública oficial. Então é importante que se conheça e se reflita sobre as consequências positivas e/ou negativas do seu uso. Segundo, porque a sua utilização na pesquisa pode tanto reafirmar as suas eventuais virtudes analíticas e normativas quanto pode apontar os seus problemas e limites. Ter esse conhecimento disponível é importante, porque possibilita o questionamento e a indicação de caminhos que contribuam para a superação dos mesmos.
}

e vegetais) e o gerenciamento de processos biológicos dos quais resulta a produção de alimentos, fibras e matérias-primas. Em função desta diversidade e complexidade torna-se difícil e muito relativo definir onde começa e termina uma atividade agrícola. É importante considerar que a base física onde estas se realizam é a unidade de produção, neste caso, o "estabelecimento agropecuário". Mesmo assim, pode-se falar de atividades agrícolas desempenhadas no próprio estabelecimento ou no estabelecimento de terceiros.

Existem também as chamadas atividades para-agrícolas, que formam um conjunto de operações, tarefas e procedimentos que implicam na transformação, beneficiamento e/ou processamento de produção agrícola (in natura ou de derivados) produzida dentro de um estabelecimento ou adquirida (em parte ou no todo) fora. As atividades para-agrícolas podem ter a finalidade de transformar a produção visando o consumo pelos próprios membros da família ou destiná-la à venda. E, finalmente, são consideradas como atividades não agrícolas/agropecuárias todas aquelas que não se enquadram na definição de atividade agrícola ou para-agrícola. Em geral, são atividades cuja realização ocorre em outros setores ou ramos da economia, sendo os mais tradicionais a indústria, o comércio e os serviços.

A interação entre atividades agrícolas, para-agrícolas e não agrícolas e a sua combinação no âmbito da família com seus membros residentes em um estabelecimento agropecuário gera a pluriatividade, que tende a ser mais intensa à medida que mais complexas e diversificadas forem a divisão do trabalho e as relações mercantis entre os agricultores e o ambiente social e econômico em que se inserem, isto é, o seu território. Os estudos realizados até o presente demonstram que são variadas as causas que podem afetar o aparecimento da pluriatividade no meio rural (PERONDI, 2007; CONTERATO, 2008; SCHNEIDER, 2009). O que permite afirmar que não existe um único tipo de pluriatividade e que sua variação decorre dos próprios fatores que estimulam o seu aparecimento. Para compreender a ampla diversidade de formas que pode assumir a 
pluriatividade em face dos condicionantes internos à unidade familiar (idade, número de membros da família, escolaridade, disponibilidade de terra, etc.) e dos contextos externos e ambientes socioeconômicos em que se desenvolve, considera-se necessário recorrer à elaboração de uma tipologia, sendo que dois tipos mais gerais puderam ser identificados com base nos dados disponíveis através do CA $2006 .{ }^{11}$

A primeira é a "pluriatividade intersetorial", decorrente do crescente processo de encadeamento e articulação da agricultura com os demais setores da economia (notadamente indústria, comércio e serviços). Expressão rural das transformações estruturais mais amplas no mercado de trabalho, está ligada a descentralização e a relocalização industrial (inclusive em espaços rurais e periurbanos), a segmentação do mercado de trabalho rural, a flexibilização das relações de trabalho (subcontratação, precarização, informalização), a expansão crescente das áreas de habitação no entorno das grandes regiões metropolitanas e ao fluxo pendular de pessoas que habitam o meio rural, mas trabalham em atividades urbanas (não agrícolas)

A segunda é a "pluriatividade agrária", que ocorre a partir da combinação de diversas atividades dentro do próprio setor agropecuário e ligadas à sua dinâmica. Para os propósitos deste trabalho, são consideradas duas formas da sua manifestação. Na primeira forma ela está relacionada à demanda crescente por serviços complementares e atividades não agrícolas gerada pelo próprio avanço do processo de modernização da agricultura (terceirização, subcontratação, aluguel de máquinas e equipamentos, contratação de serviços assessórios, etc.). A segunda forma integra as atividades para-agrícolas, tratando-se geralmente de uma evolução da produção para autoconsumo que era produzida para a sub-

11. Há também um tipo de pluriatividade "tradicional ou camponesa", cuja existência é determinada por um específico modo de vida e organização da produção, associado às "sociedades camponesas", e não pelo processo mais geral de mercantilização da agricultura e da vida rural, sobre o qual recai nosso foco (SCHNEIDER, 2009). sistência da família que passa a ser destinada à venda, dando origem às chamadas "agroindústrias familiares rurais".

\section{Pluriatividade: identificação, mensuração e caracterização}

A caracterização da pluriatividade inicia pelo dimensionamento do universo dos estabelecimentos agropecuários pluriativos, segundo a agricultura familiar e não familiar. As Tabelas 1 e 2 indicam a abrangência do fenômeno da pluriatividade no Brasil em termos absolutos e percentuais, mensurando o universo de estabelecimentos pluriativos no total dos estabelecimentos agropecuários e distinguindo entre as duas categorias referidas. De acordo com os dados do Censo Agropecuário 2006, naquele ano foram recenseados 5.175.489 estabelecimentos agropecuários em todo Brasil, sendo que 1.910.131, isto é, 37\%, podem ser considerados pluriativos.

Considerando o total de estabelecimentos agropecuários existentes no Brasil, 84,4\% (4.367.902) podem ser classificados como pertencentes a categoria agricultura familiar e 15,6\% (807.587) como de agricultura não familiar. Entre os estabelecimentos familiares, $34,1 \%$ (1491.080) são pluriativos, ao passo que entre os não familiares chega a 51.9\% (419.051) o número de estabelecimentos assim classificados.

Essa verificação nos alertou para uma intrigante questão de natureza teórica. A quase totalidade dos estudos sobre pluriatividade no Brasil sempre considerou o fenômeno da pluriatividade como uma especificidade da agricultura familiar, de modo que sua análise nunca foi estendida à outros segmentos, que neste trabalho estão agregados sob a alcunha de agricultura não familiar. Podem-se arrolar algumas razões, que interrelacionadas, ajudam a explicar essa lacuna analítica. A primeira razão é que a maior parte dos estudos que tentaram quantificar a pluriatividade no Brasil utilizaram como fonte de dados as PNAD, que não operam objetivamente essa 
650 - Caracterização da Pluriatividade e dos Plurirrendimentos da Agricultura Brasileira a partir do Censo Agropecuário 2006

Tabela 1. Estabelecimentos Agropecuários Pluriativos e Não Pluriativos - Brasil, Regiões Sul e Nordeste

\begin{tabular}{lcccccc}
\hline \multicolumn{1}{c}{ Recorte } & Não pluriativos & $\mathbf{( \% )}$ & Pluriativos & $\mathbf{( \% )}$ & Total & $\mathbf{( \% )}$ \\
\hline Brasil & 3.265 .358 & 63,0 & 1.910 .131 & 37,0 & 5.175 .489 & 100,0 \\
Região Sul & 650.996 & 64,7 & 355.185 & 35,3 & 1.006 .181 & 100,0 \\
Região Nordeste & 1.546 .517 & 63,0 & 907.489 & 37,0 & 2.454 .006 & 100,0 \\
\hline
\end{tabular}

Fonte: Censo Agropecuário 2006 ("tabulação especial” realizada pelo IBGE).

Elaboração: Projeto Ipea/PGDR 2010/2011.

Tabela 2. Estabelecimentos Totais e Pluriativos, segundo a Agricultura Familiar e Agricultura Não Familiar Brasil e regiões Sul e Nordeste

\begin{tabular}{lccccc}
\hline \multicolumn{1}{c}{ Recorte } & Variáveis & Agricultura Familiar & $\mathbf{( \% )}$ & Agricultura Não Familiar & $\mathbf{( \% )}$ \\
\hline \multirow{2}{*}{ Brasil } & Total & 4.367 .902 & 100,0 & 807.587 & 100,0 \\
& Pluriativos & 1.491 .080 & 34,1 & 419.051 & 51,9 \\
\hline \multirow{2}{*}{ Região Sul } & Total & 849.997 & 100,0 & 156.184 & 100,0 \\
& Pluriativos & 275.945 & 32,5 & 79.240 & 50,7 \\
\hline \multirow{2}{*}{ Região Nordeste } & Total & 2.187 .295 & 100,0 & 266.711 & 100,0 \\
& Pluriativos & 752.040 & 34,4 & 155.449 & 58,3 \\
\hline
\end{tabular}

Fonte: Censo Agropecuário 2006 ("tabulação especial” realizada pelo IBGE).

Elaboração: Projeto Ipea/PGDR 2010/2011.

distinção. Na PNAD os domicílios são classificados segundo o critério de ocupação, sendo distinguidos entre empregadores, empregados e ocupados por conta própria. De maneira aproximada, aqueles enquadrados no primeiro grupo eram tomados como integrantes da agricultura patronal, outros eram enquadrados no grupo dos assalariados rurais e um terceiro grupo, os ocupados por conta própria, eram enquadrados como agricultores familiares. A segunda razão explicativa é que os estudos de caso sobre pluriatividade geralmente focalizavam a agricultura familiar, justamente em regiões como no Sul e no Nordeste do Brasil, que em conjunto abrigam praticamente $80 \%$ da agricultura familiar nacional, havendo pouco interesse nos outros segmentos. E a terceira e principal razão, é que a noção de pluriatividade "surgiu sendo evocada para compreender as formas através das quais as explorações de caráter familiar reagem diante das adversidades do ambiente social e econômico em que se acham inseridas, bem como das pressões internas decorrentes da necessidade de assegurar o atendimento das necessidades materiais do núcleo familiar"12 não fazendo sentido, portanto, falar de pluriatividade na agricultura patronal ou empresarial. ${ }^{13}$

Assim, em face da ausência de pesquisas específicas sobre as características - e a própria possibilidade teórica - da pluriatividade em estabelecimentos não familiares, o máximo que podemos fazer em termos interpretativos no momento é levantar algumas hipóteses, que obviamente precisam ser aprofundadas por estudos vindouros. Acreditamos que uma parcela expressiva dos

12. Agradecemos a um dos pareceristas anônimos da Revista SOBER por chamar a atenção e enfatizar este aspecto, que nos pareceu tão relevante a ponto de reproduzimos a frase do seu autor no original.

13. Aqui é necessário fazer uma ressalva, estribada na proposição de Ploeg (2008), para quem a agricultura familiar pode desenvolver diferentes modos de fazer agricultura, sendo que o principal fator de sua diferenciação é o grau de mercantilização e não as relações de propriedade. A "forma camponesa" opera em uma trajetória histórica de "reprodução relativamente autônoma", em que a força de trabalho e os recursos necessários para cada ciclo de produção são resultados do ciclo precedente. A "forma empresarial" opera em uma trajetória histórica de "reprodução dependente do mercado", onde os recursos são necessariamente mobilizados como mercadorias. 
estabelecimentos agropecuários não familiares pluriativos possam ser unidades de produção cuja propriedade pertence a pessoas ocupadas em outras atividades econômicas, como os profissionais liberais (médicos, dentistas, advogados, etc.) que residem no meio rural e trabalham nas imediações urbanas. Também podem ser profissionais das ciências agrárias (agrônomos, veterinários, zootecnistas), muitos dos quais são proprietários de estabelecimentos rurais e possuem atividades econômicas nestas unidades, em geral utilizando força de trabalho contratada. Há ainda a possibilidade de que muitos destes estabelecimentos não familiares sejam, na verdade, sítios ou chácaras utilizados ao mesmo tempo para lazer e residência de pessoas que não são especificamente agricultores (os chamados "neorurais"), não constituindo necessariamente uma unidade de produção agropecuária pluriativa. Na maioria dos casos, de qualquer maneira, trata-se de uma nova função que o meio rural vem adquirindo, que é ser espaço de moradia e lazer, e também de negócios, por grupos sociais que não são agricultores familiares (GRAZIANO DA SILVA, 1999).

Apesar de uma variada gama de possibilidades que poderiam ajudar a explicar a incidência da pluriatividade em estabelecimentos agropecuários não familiares, o fato relevante é a constatação da heterogeneidade e diversidade do meio rural brasileiro, que se caracteriza tanto por velhas como novas e emergentes formas de ruralidade (WANDERLEY, 2004). Por um lado, não se pode ignorar que as distintas formas de ocupação que combinam atividades agrícolas e não agrícolas poderiam sim manifestar-se enquanto pluriatividade em estabelecimentos não familiares. Por outro lado, é claro que aceitar essa possibilidade abre para controvérsias, pois certas situações guardam pouca similitude com a caracterização corrente do fenômeno da pluriatividade no rural. No caso da agricultura propriamente patronal, em que o proprietário e sua família dificilmente residem no meio rural, seria equivocado chamar de pluriatividade o fenômeno de diversificação das ocupações que surge pela sua inser- ção em distintos ramos econômicos (agricultura, indústria, comércio, finanças) que caracterizam o negócio capitalista, no qual o empresário busca diversificar sua carteira de ativos de acordo com as taxas diferenciadas de rentabilidade do capital que administra. Ou talvez mesmo no caso na agricultura empresarial, como ocorre com os profissionais liberais ou profissionais das ciências agrárias, em que não se trata de pessoas cujo principal meio de vida e fonte de renda provém da agricultura ou de outras atividades não agrícolas realizadas no meio rural.

Neste sentido, o que deve ficar claro é que não estamos à procura da pluriatividade em estabelecimentos patronais com o fito de provar a tese da existência da pluriatividade no "agronegócio". Porém, o Censo Agropecuário de 2006 indica a existência de um grupo de estabelecimentos agropecuários que usam predominantemente o trabalho assalariado no empreendimento que conduzem, mas cujos membros da família podem muito bem residir na propriedade e envolver-se ou não em outras atividades urbanas (não agrícolas) sem, contudo, deixar de atuar em atividades de gestão (não agrícolas) e eventualmente em atividades produtivas (agrícolas). Não é difícil imaginar esse tipo de situação de "pluriatividade patronal", especialmente nas zonas de expansão agrícola do Centro-Oeste ou do Nordeste, ou mesmo em algumas partes da região Sul, como aventam Herédia, Palmeira e Leite (2010).

Não obstante, o que mais nos interessa é fazer uma análise desses estabelecimentos classificados como não familiares que permita perscrutar suas características e verificar em que medida alguns estabelecimentos que foram classificados como ANF podem pertencer, na verdade, também à AF. Esta hipótese surgiu ao se verificar que os critérios que o IBGE utiliza para classificar os estabelecimentos agropecuários familiares estão apoiados na definição da Lei 11.326 e do próprio Pronaf. Entre os critérios de definição do que seja um agricultor familiar, um deles sugere que os estabelecimentos que possuírem mais da metade da renda proveniente de atividades não agrícolas devem ser excluídos da classificação de agricul- 
tura familiar para fins de delimitação dos beneficiários, sendo automaticamente classificados como estabelecimentos não familiares. Ora, vale notar que desde 2011 este critério sofreu uma alteração, vindo a permitir a inclusão dos estabelecimentos pluriativos no universo dos estabelecimentos de agricultura familiar sem que, contudo, fosse modificada a definição utilizada pelo IBGE para delimitar o universo da agricultura familiar, que é de 2006. Em face disso, estamos levantando a hipótese de que muitos estabelecimentos agropecuários pluriativos não familiares podem ser, na verdade, unidades de agricultores familiares. $\mathrm{Na}$ classificação operada segundo a Lei 11.326 pode ter ocorrido que os estabelecimentos de agricultura familiar que registraram que mais da metade de renda houvera sido obtida em atividades não agrícolas foram classificados como estabelecimentos agropecuários não familiares.

Na região Sul do Brasil, formada pelos estados do Paraná, Santa Catarina e Rio Grande do Sul, há 1.006.181 estabelecimentos agropecuários, que representa $19,4 \%$ do total dos estabelecimentos do país. Dentre estes, 35,3\% (355.185) são estabelecimentos pluriativos. Os 849.997 estabelecimentos de agricultores familiares recenseados nessa região representam $84,5 \%$ do total, enquanto os 156.184 estabelecimentos de agricultores não familiares representam 15,5\%. A tendência anteriormente apontada para o Brasil como um todo, portanto, também se confirma para a região Sul, embora de maneira mais equilibrada entre as duas categorias: entre os estabelecimentos de AF 32,5\% (275.945) são pluriativos, enquanto que entre os estabelecimentos de ANF, 50,7\% (79.240) o são.

Já a região Nordeste é formada por nove (9) estados: Alagoas, Bahia, Ceará, Maranhão, Paraíba, Piauí, Pernambuco, Rio Grande do Norte e Sergipe. São 2.454.006 estabelecimentos agropecuários no Nordeste, $47,41 \%$ do total de estabelecimentos do país, sendo que 37\% (907.489) destes são pluriativos. No Nordeste também se encontra a maior concentração de agricultores familiares do Brasil: $89,1 \%$ (2.187.295) do total de estabelecimentos da região pertencem à categoria $\mathrm{AF}$, dos quais $34,4 \%$ (752.040) são pluriativos, e apenas $10,9 \%$ (266.711) dos estabelecimentos pertencem à categoria $\mathrm{ANF}$, dos quais 58,3\% (155.449) são pluriativos. Ou seja, a tendência apontada para o Brasil e confirmada na região Sul, também se confirma para o Nordeste, porém a incidência de pluriatividade em ambas as categorias está acima da média nacional e apresenta ainda maior intensidade entre os estabelecimentos de ANF.

Com a Figura 1 pode-se comparar os dados para cada unidade territorial, mostrando a distribuição dos estabelecimentos pluriativos entre as duas categorias. Verifica-se que há maior convergência percentual entre Brasil e Sul, em que aproximadamente $78 \%$ dos estabelecimentos pluriativos são de $\mathrm{AF}$ e $22 \%$ de $\mathrm{ANF}$, enquanto que no Nordeste a proporção é de $82,9 \%$ para $17,1 \%$.

Na sequencia, com base nos dados da Tabela 3, abordam-se os tipos de atividades que são desenvolvidas dentro dos estabelecimentos pluriativos de agricultura familiar e de agricultura não familiar e, desse modo, os próprios tipos de pluriatividade, já identificados em trabalhos como Schneider (2009), Conterato (2008) e Escher (2011), para alguns territórios do Sul do Brasil, através de estudos de caso com fontes primárias de dados quantitativos.

De acordo com os dados do CA 2006, em $54,8 \%$ dos estabelecimentos pluriativos de agricultura familiar, os produtores e/ou algum dos membros da família realizam atividades não agropecuárias, sendo que em $52 \%$ dos estabelecimentos eles realizam apenas atividades não agropecuárias e em $2,8 \%$ realizam tanto atividades não agropecuárias como agropecuárias. Esses estabelecimentos são designados pluriativos intersetoriais, pois além de estarem ocupados no setor agropecuário, também se ocupam em outras atividades, especialmente nos setores de indústria, comércio e serviços. Mas há um grupo de $45,2 \%$ desses estabelecimentos que realizam atividades fora do estabelecimento, só que apenas dentro do próprio setor agropecuário, os quais são designados pluriativos agrários. Já entre os produtores e membros das famílias dos estabelecimentos pluriativos de agricultura não 
Figura 1. Estabelecimentos Pluriativos - proporção entre Agricultura Familiar e Agricultura Não Familiar no Brasil e nas Regiões Sul e Nordeste

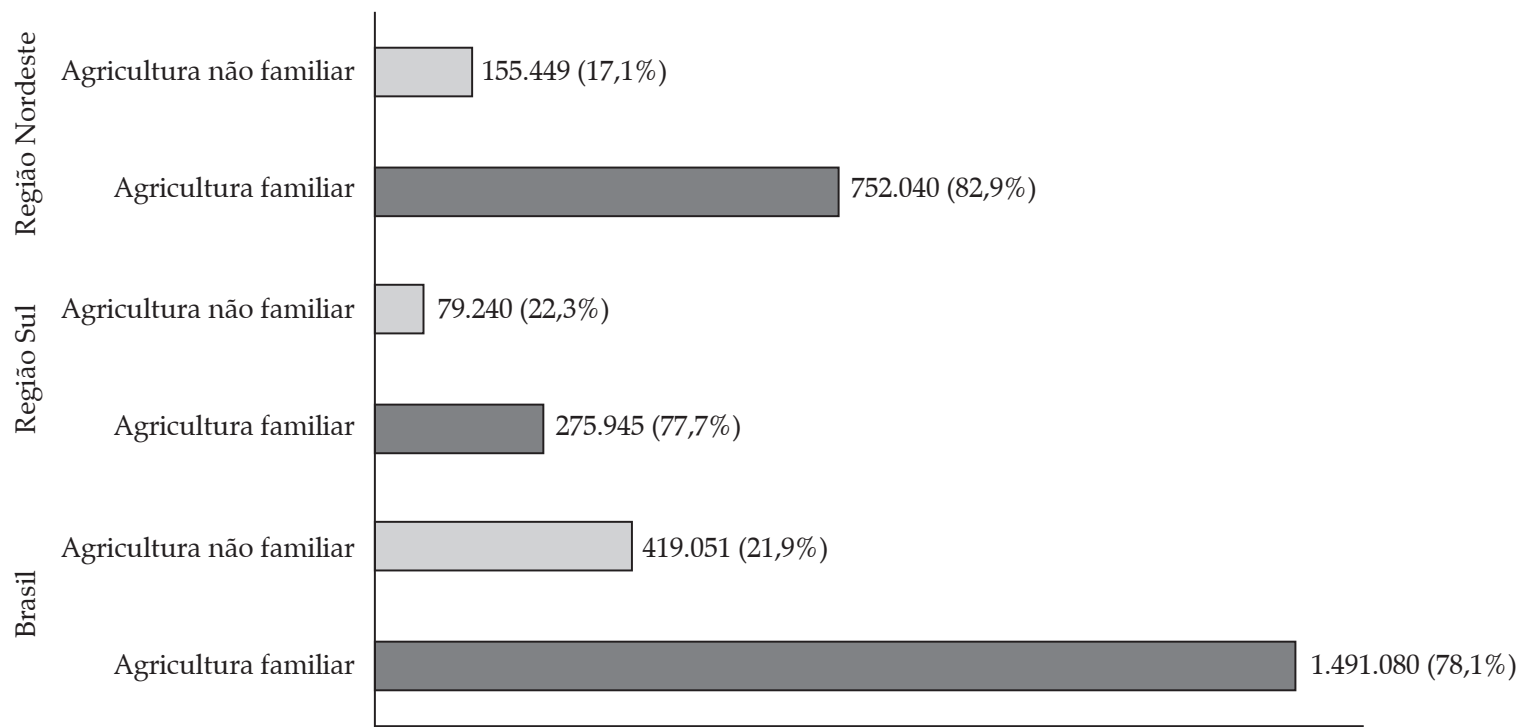

Estabelecimentos

Fonte: Censo Agropecuário 2006 ("tabulação especial" realizada pelo IBGE).

Elaboração: Projeto Ipea/PGDR 2010/2011.

Tabela 3. Estabelecimentos Pluriativos no Brasil e nas regiões Sul e Nordeste por Agricultura Familiar e Agricultura Não Familiar, segundo o tipo de atividade (e de pluriatividade)

\begin{tabular}{|c|c|c|c|c|c|}
\hline \multirow{2}{*}{ Recorte } & \multirow{2}{*}{ Variáveis } & Agricultura & \multirow{2}{*}{$(\%)$} & Agricultura & \multirow{2}{*}{$(\%)$} \\
\hline & & Familiar & & Não Familiar & \\
\hline \multirow{4}{*}{ Brasil } & Agropecuária (Agrária) & 674.249 & 45,2 & 140.323 & 33,5 \\
\hline & Não agropecuária (Intersetorial) & 774.909 & 52 & 262.260 & 62,6 \\
\hline & Agropecuária e Não agro (Intersetorial) & 41.922 & 2,8 & 16.467 & 3,9 \\
\hline & Total & 1.491 .080 & 100 & 419.050 & 100 \\
\hline \multirow{4}{*}{$\begin{array}{l}\text { Região } \\
\text { Sul }\end{array}$} & Agropecuária (Agrária) & 101.084 & 36,6 & 25.909 & 32,7 \\
\hline & Não agropecuária (Intersetorial) & 169.101 & 61,3 & 50.647 & 63,9 \\
\hline & Agropecuária e Não agro (Intersetorial) & 5.760 & 2,1 & 2.684 & 3,4 \\
\hline & Total & 275.945 & 100 & 79.240 & 100 \\
\hline \multirow{4}{*}{$\begin{array}{l}\text { Região } \\
\text { Nordeste }\end{array}$} & Agropecuária (Agrária) & 384.138 & 51,1 & 59.832 & 38,5 \\
\hline & Não agropecuária (Intersetorial) & 345.243 & 45,9 & 89.422 & 57,5 \\
\hline & Agropecuária e Não agro (Intersetorial) & 22.659 & 3 & 6.195 & 4 \\
\hline & Total & 752.040 & 100 & 155.449 & 100 \\
\hline
\end{tabular}

Fonte: Censo Agropecuário 2006 ("tabulação especial" realizada pelo IBGE).

Elaboração: Projeto Ipea/PGDR 2010/2011.

familiar do Brasil, $66,5 \%$ podem ser considerados pluriativos intersetoriais, sendo que $62,6 \%$ realizam apenas atividades não agropecuárias e 3,9\% realizam atividades não agropecuárias e também atividades agropecuárias. Mas também há 33,5\% desses estabelecimentos que realizam atividades eventualmente fora do próprio estabelecimento, mas de qualquer maneira vinculadas ao setor agropecuário, ou seja, são estabelecimentos pluriativos agrários.

Isto requer uma breve análise, através da qual os tipos de pluriatividade são contextualiza- 
dos, para que o significado desses números possa ser melhor compreendido. Em termos históricos, a pluriatividade aqui denominada intersetorial remonta o "putting out system", sendo a figura do "worker-peasant" sua forma social típica. No período mais recente, contudo, este tipo de pluriatividade decorre de dois processos macro. O primeiro está relacionado à descentralização industrial, que decorre principalmente da flexibilização dos processos produtivos e da diversificação crescente das economias locais. $\mathrm{O}$ deslocamento das empresas para os espaços rurais e periurbanos deve-se a vários fatores, em geral associados à procura por força de trabalho mais barata e proximidade de fontes de matéria prima. A segmentação do mercado de trabalho, a subcontratação, a informalização e a precarização das relações de trabalho geralmente acompanham este processo. E o segundo processo é a rurbanização ou "commuting system", que, embora em parte decorrente do processo anterior, está relacionado à expansão crescente das áreas de habitação no entorno das grandes regiões metropolitanas e do fluxo diário e pendular das pessoas que habitam no meio rural, mas trabalham em atividades não agrícolas. A rurbanização transforma as áreas rurais e lhes imprime uma nova dinâmica, caracterizada pela valorização imobiliária e pelo crescimento da prestação de serviços. Em razão disso, os mercados de trabalho rural e urbano vão se integrando e se homogeneizando e a pluriatividade intersetorial das famílias agricultoras torna-se a característica mais saliente deste processo, trazendo para o espaço rural um conjunto de novas relações de trabalho, num contexto territorial de diversificação econômica. Desnecessário dizer que essas mudanças estruturais nas formas de ocupação do trabalho no meio rural afetam, de distintas maneiras, tanto agricultores familiares como não familiares.

Enquanto a pluriatividade agrária, por sua vez, agrega dois tipos de atividades: as de "base agrária" e as "para-agrícolas". Contudo, neste tipo de pluriatividade, o crescimento de ambas as atividades tem em comum o fato de estarem ligadas às transformações na dinâmica do próprio setor agropecuário, que nas últimas duas décadas ampliaram-se rapidamente no Brasil, coincidindo com a organização e gestão do setor no esquema de cadeias de valor que integram produção, beneficiamento, distribuição e comercialização.

As atividades de base agrária se expandem: i) com a terceirização de etapas ou fases dos processos produtivos na agricultura, o que implica, por exemplo, no aluguel de máquinas e equipamentos e na contratação de serviços prestados por terceiros para execução de tarefas de plantio, colheita, manejo e transporte, que antes eram realizadas pelos próprios membros da família ou recorrendo a alguma forma de ajuda mútua; ii) com a contratação de pessoas que moram no meio rural e integram famílias de agricultores para atuar, por exemplo, como tratoristas, armazenadores, ensacadores, pessoal de administração, etc.; e também iii) através da informalidade e da precariedade da venda de força de trabalho no meio rural, em larga medida decorrente da sazonalidade dos processos de produção na agricultura, onde existe um conjunto de atividades não agrícolas esporádicas e intermitentes, que não tem jornada de trabalho pré-estabelecida (artesanato, vendedores ambulantes, diaristas, empreiteiros, etc.). Estes processos afetam distintamente os agricultores familiares e não familiares, dependendo da forma como os indivíduos de cada categoria se posicionam no mercado de trabalho rural.

Já as atividades para agrícolas se expandem à medida que a produção de produtos para autoconsumo e subsistência da família (derivados de leite, cana, carnes, frutas e outros) passa a ser destinada à venda, crescendo e começando a ocupar espaços fora do âmbito doméstico e a tornar-se uma atividade independente de transformação de alimentos, inaugurando uma nova jornada de trabalho, rotinas diferenciadas e novas ocupações que, combinadas com a agricultura como atividade principal, gera a pluriatividade. No Brasil, estes empreendimentos vêm sendo chamados de "agroindústrias rurais familiares", quase sempre de pequeno porte (mas com escalas variáveis) e organizados em uma diversidade 
de formas (individuais, cooperativas, associações, redes). Este tipo de pluriatividade tende a aparecer onde predomina a agricultura familiar e onde os mercados de trabalho em atividades não agrícolas intersetoriais são débeis ou quase inexistentes, surgindo como uma alternativa de emprego, ocupação e renda para os agricultores que vislumbram uma forma diferenciada de inserção econômica e mercantil.

Na região Sul, 63,4\% dos estabelecimentos familiares do Sul podem ser considerados pluriativos intersetoriais numa proporção relativamente maior do que aquela que ocorre no Brasil como um todo: $61,3 \%$. As pessoas dos outros $36,6 \%$ (uma proporção menor do que ocorre no Brasil) exercem apenas atividades agropecuárias fora dos seus estabelecimentos, que podem ser considerados, portanto, pluriativos agrários. E entre dos estabelecimentos pluriativos de agricultura não familiar da região Sul, em $67,3 \%$ deles os produtores ou membros exercem atividades não agropecuárias, podendo ser considerados pluriativos intersetoriais, enquanto os outros 32,7\% realizam apenas atividades agropecuárias fora do estabelecimento, sendo considerados pluriativos agrários.

Na região Nordeste, em $48,9 \%$ dos estabelecimentos pluriativos de agricultura familiar seus produtores e/ou membros da família exercem atividades não agropecuárias, podendo ser considerados pluriativos intersetoriais. Os outros 51,1\% realizam apenas atividades agropecuárias fora do estabelecimento. Ou seja, no Nordeste os estabelecimentos pluriativos de agricultura familiar são predominantemente de base agrária, diferente do que ocorre no Brasil e, sobretudo, na região Sul. Por sua vez, entre os estabelecimentos pluriativos de agricultura não familiar, em 61,5\% deles as pessoas exercem também atividades não agropecuárias, podendo ser considerados pluriativos intersetoriais, enquanto $38,5 \%$ são pluriativos agrários, realizando apenas atividades fora do próprio estabelecimento.

Como corolário, pode-se concluir que na região Nordeste a pluriatividade agrária é relativamente mais significativa do que na região Sul e no Brasil, ao passo que na região Sul a presença de estabelecimentos pluriativos intersetoriais é maior do que na região Nordeste e no Brasil. ${ }^{14}$ Sabe-se que a natureza e a evolução das diferentes formas que a pluriatividade assume em diferentes lugares, regiões ou territórios variam de acordo com as suas raízes históricas, as suas estruturas sociais e as dinâmicas de suas economias e mercados de trabalho. Mesmo nos casos em que a qualidade das ocupações é "ruim", como no Nordeste - onde, segundo Nascimento et al. (2008) as ocupações agrícolas são piores que as não-agrícolas -, a força de trabalho passa a ser a principal mercadoria de que os agricultores, principalmente os familiares, dispõem para oferecer no mercado em troca de alguma remuneração. Contudo, mesmo nestes casos, o recurso à pluriatividade não implica necessariamente na proletarização dos indivíduos ${ }^{15}$, embora implique decisivamente no aprofundamento da inserção destes nos circuitos mercantis, de acordo com as características existentes no território, podendo ocorrer concomitantemente em mercados de produtos e de trabalho. Seja como for, estudos até aqui realizados sobre pluriatividade na AF permitem concluir que se trata de um fenômeno estável e diversificado que, embora exista desde longo tempo no meio rural, apenas recentemente passou a ser estudado sob esta denominação (SCHNEIDER, 2007; ANJOS e CALDAS, 2007). Também já sabe-se que se trata de uma estratégia de reprodução social das famílias

14. Poderiam ser levantadas hipóteses explicativas dessas diferenças relativas entre Sul e Nordeste, com foco tanto em fatores internos, relativos à própria instituição familiar (sexo, número de membros, idade, níveis de instrução, terra), como em fatores externos, relativos ao ambiente econômico das regiões (graus de diversificação e dinamismo das economias e disponibilidade de empregos nos diferentes setores). Todavia isso está além dos propósitos deste artigo e pode ser objeto de pesquisa em estudos futuros, nossos e de outros autores.

15. Segundo Ellis (2000), a pluriatividade pode ser entendida como uma estratégia de reação, diante de uma situação de risco ou de vulnerabilidade, ou então como uma estratégia de adaptação, quando os indivíduos membros de uma família possuem certos atributos que lhes permitem optar e decidir frente a um conjunto de oportunidades e possibilidades de inserção laboral. 
rurais, que recorrem às atividades externas por diferentes razões (adaptação, reação, estilo de vida), não sendo a pobreza o único fator determinante, nem o principal, em contraste com o que recentemente voltou-se a argumentar (como em NASCIMENTO e CARDOZO, 2007).

Quanto a ocupação da mão de obra nos estabelecimentos pluriativos de AF e ANF no Brasil e nas regiões Sul e Nordeste, o pessoal ocupado total foi dividido em duas categorias pelo tipo de relação de trabalho vigente: o pessoal ocupado com laços de parentesco com o produtor, que se refere aos próprios membros da família do mesmo que exercem atividades nos estabelecimentos; e o pessoal ocupado sem laços de parentesco com o produtor, que se refere mão de obra empregada sob relação contratual e condição de assalariamento com os chefes dos estabelecimentos, mas que não são seus parentes.

Na Tabela 4 constam algumas características da ocupação dos membros da família nos estabelecimentos pluriativos do Brasil e das regiões Sul e Nordeste. No Brasil, 3.767.760 de pessoas com laços de parentesco com o produtor estão ocupadas nos 1491.080 estabelecimentos pluriativos de agricultura familiar, o que representa $81,3 \%$ do total da força de trabalho familiar ocupada na agricultura (IBGE, 2009a). De todas as pessoas ocupadas nos estabelecimentos dessa categoria, $76,3 \%$ residem nos mesmos, mas apenas 3,7\% recebem salários e apenas 3,0\% estão ocupadas em atividades não agropecuárias. $\mathrm{Ou}$ seja, a maior parte do pessoal ocupado no meio rural está na agricultura familiar, sendo que entre esses, a maioria é formada pelos próprios membros das famílias. E nos 419.051 estabelecimentos pluriativos de agricultura não familiar brasileiros estão ocupadas 868.990 pessoas com laços de parentesco com o produtor: $18,7 \%$ da força de trabalho familiar ocupada na agricultura. $62,0 \%$ delas residem nos estabelecimentos, sendo que 14\% recebem salários e 4,5\% estão ocupadas em atividades não agropecuárias. Esse expressivo número de membros da família que residem nos estabelecimentos agropecuários não familiares reforça a necessidade de aprofundar as pesquisas sobre a pluriatividade nos mesmos, como já afirmado anteriormente.

Em relação a região Sul, 659.138 pessoas com laços de parentesco com os produtores estão ocupadas nos 275.945 estabelecimentos de agricultura familiar: o que representa $79,1 \%$ do total da força de trabalho familiar rural ocupada na agricultura da região. De todas as pessoas ocupadas nos estabelecimentos dessa categoria, 82,1\% residem nos mesmos, sendo que 5,3\% recebem salários e apenas $4,7 \%$ estão ocupadas em atividades não agropecuárias. E nos 79.240 estabele-

Tabela 4. Características da ocupação dos membros da família (com laços de parentesco) nos Estabelecimentos Pluriativos no Brasil e nas regiões Sul e Nordeste, por Agricultura Familiar e Agricultura Não Familiar

\begin{tabular}{|c|c|c|c|c|c|}
\hline Recorte & Variáveis & Agricultura Familiar & $(\%)$ & Agricultura Não Familiar & $(\%)$ \\
\hline \multirow{4}{*}{ Brasil } & Residentes & 2.873 .808 & 76,3 & 539.137 & 62 \\
\hline & Recebem salário & 139.693 & 3,7 & 75.616 & 8,7 \\
\hline & Em atividade não agropecuária & 112.536 & 3,0 & 39.292 & 4,5 \\
\hline & Total & 3.767 .760 & 100 & 868.990 & 100 \\
\hline \multirow{4}{*}{$\begin{array}{l}\text { Região } \\
\text { Sul }\end{array}$} & Residentes & 541.114 & 82,1 & 113.664 & 65,3 \\
\hline & Recebem salário & 35.119 & 5,3 & 16.468 & 9,5 \\
\hline & Em atividade não agropecuária & 31.180 & 4,7 & 8.868 & 5,1 \\
\hline & Total & 659.138 & 100 & 174.187 & 100 \\
\hline \multirow{4}{*}{$\begin{array}{l}\text { Região } \\
\text { Nordeste }\end{array}$} & Residentes & 1.450 .716 & 73,5 & 226.339 & 64,9 \\
\hline & Recebem salário & 59.151 & 3 & 20.504 & 5,9 \\
\hline & Em atividade não agropecuária & 38.630 & 2 & 10.999 & 3,2 \\
\hline & Total & 1.974 .000 & 100 & 348.943 & 100 \\
\hline
\end{tabular}

Fonte: Censo Agropecuário 2006 ("tabulação especial” realizada pelo IBGE).

Elaboração: Projeto Ipea/PGDR 2010/2011. 
cimentos pluriativos de agricultura não familiar sulinos estão ocupadas 174.187 pessoas com laços de parentesco com o produtor: $20,9 \%$ da força de trabalho familiar ocupada na agricultura. $65,3 \%$ delas residem nos estabelecimentos, sendo que 9,5\% recebem salários e 5,1\% estão ocupadas em atividades não agropecuárias.

Já em relação ao Nordeste, 1.974 .000 pessoas estão ocupadas nos 752.040 estabelecimentos de agricultura familiar da região: $85 \%$ do total de 2.322.934 pessoas com laços de parentesco com os produtores de estabelecimentos pluriativos. $73,5 \%$ delas residem nos estabelecimentos e apenas $2 \%$ exercem atividades não agropecuárias. 348.943 pessoas estão ocupadas nos 155.449 estabelecimentos pluriativos de agricultura não familiar do Nordeste: $15 \%$ do total do pessoal ocupado com laços de parentesco com os produtores. $64,9 \%$ dessas pessoas residem no estabelecimento da família, sendo que 5,9\% recebem salários e $3,2 \%$ exercem atividades não agropecuárias.
Para se ter uma análise mais detalhada, algumas características do pessoal ocupado por meio de regimes de assalariamento ou de parceria nos estabelecimentos pluriativos do Brasil e das regiões Sul e Nordeste podem ser observadas na Tabela 5.

Nos estabelecimentos pluriativos de AF do Brasil estão ocupadas 511.072 pessoas: 30,8\% das ocupadas nesse tipo de regime de trabalho. Sendo que $89,4 \%$ delas são contratadas para empregos temporários e apenas 10,6\% para empregos permanentes e outros. Apenas 13,3\% deles residem nos estabelecimentos e 3,8\% atuam em atividades não agropecuárias. 1.150 .741 pessoas estão ocupadas como empregados contratados nos estabelecimentos pluriativos de ANF no Brasil: $69 \%$ desse tipo de emprego rural. Desse universo 50,2\% são empregados permanentes e 45,3\% empregados temporários. 34,5\% desse pessoal reside nos estabelecimentos e 3,3\% atua em atividades não agropecuárias. Esses dados

Tabela 5. Características da ocupação dos empregados contratados (sem laços de parentesco) nos Estabelecimentos Pluriativos no Brasil e nas regiões Sul e Nordeste, por Agricultura Familiar e Agricultura Não Familiar

\begin{tabular}{llcccc}
\hline Recorte & \multicolumn{1}{c}{ Variáveis } & Agricultura Familiar & $\mathbf{( \% )}$ & Agricultura Não Familiar & $\mathbf{( \% )}$ \\
\hline \multirow{6}{*}{ Brasil } & Empregado permanente & 41.725 & 8,2 & 577.734 & 50,2 \\
& Empregado temporário & 457.058 & 89,4 & 520.767 & 45,3 \\
& Empregado parceiro & 3.946 & 0,8 & 36.408 & 3,2 \\
& Empregado outra condição & 8.343 & 1,6 & 15.832 & 1,4 \\
& Total & 511.072 & 100 & 1.150 .741 & 100 \\
& Em atividade não agropecuária & 19.296 & 3,8 & 37.857 & 3,3 \\
& Residentes & 68.172 & 13,3 & 397.502 & 34,5 \\
\hline \multirow{5}{*}{ Região } & Empregado permanente & 6.819 & 12,6 & 80.252 & 56,2 \\
& Empregado temporário & 45.955 & 84,7 & 57.215 & 40,1 \\
& Empregado parceiro & 660 & 1,2 & 3.585 & 2,5 \\
& Empregado outra condição & 810 & 1,5 & 1.629 & 1,1 \\
& Total & 54.244 & 100 & 142.681 & 100 \\
& Em atividade não agropecuária & 3.366 & 6,2 & 7.334 & 5,1 \\
& Residentes & 9.034 & 16,7 & 54.496 & 38,2 \\
\hline \multirow{5}{*}{ Região } & Empregado permanente & 11.054 & 3,6 & 148.484 & 40,4 \\
& Empregado temporário & 287.971 & 94,5 & 203.167 & 55,2 \\
& Empregado parceiro & 1.236 & 0,4 & 10.370 & 2,8 \\
& Empregado outra condição & 4.355 & 1,4 & 5.715 & 1,6 \\
& Total & 304.616 & 100 & 367.736 & 100 \\
& Em atividade não agropecuária & 8.791 & 2,9 & 10.074 & 2,7 \\
& Residentes & 27.768 & 9,1 & 94.805 & 25,8 \\
\hline
\end{tabular}

Fonte: Censo Agropecuário 2006 ("tabulação especial” realizada pelo IBGE).

Elaboração: Projeto Ipea/PGDR 2010/2011. 
só reforçam uma conclusão quase autoevidente e plenamente reconhecida: a de que a os estabelecimentos de agricultura não familiar (inclusive os pluriativos) são os que mais utilizam o recurso ao trabalho assalariado (principalmente permanente), embora ocupem menos força de trabalho.

Na região Sul, as 54.244 pessoas ocupadas como empregados nos estabelecimentos pluriativos de AF representam 27,5\% do total dos trabalhadores contratados na agricultura, sendo que desses $84,7 \%$ são empregados temporários e entre os $15,3 \%$ restantes, $12,6 \%$ são permanentes. As 142.681 pessoas contratadas em estabelecimentos da ANF representam 72,5\% do total de pessoas ocupadas nesse regime de trabalho, sendo que $56,2 \%$ desses são empregados permanentes e 40,1\% empregados temporários.

E na região Nordeste, entre o pessoal ocupado como empregados nos estabelecimentos pluriativos, $304.616(45,3 \%)$ estão em estabelecimentos de AF, e $367.736(54,7 \%)$ em estabelecimentos de ANF. Só que a agricultura familiar contrata 94,5\% destes na condição de empregados temporários e apenas 3,6\% como permanentes, enquanto que a não familiar tem $40,4 \%$ dos seus trabalhadores contratados em condição permanente e 55,2\% em condição temporária. No caso dos estabelecimentos familiares apenas $9,1 \%$ deles reside no estabelecimento, já que a maioria dos empregados são temporários, ao passo que nos estabelecimentos não familiares, $25,8 \%$ dos empregados são residentes.

\section{Plurirrendimentos: diversidade das fontes de renda e receitas}

Nesta seção analisa-se a composição das receitas dos estabelecimentos pluriativos para as categorias de agricultura familiar e agricultura não familiar. O Quadro 1 traz uma classificação de todas as fontes de receitas que formam a receita total dos estabelecimentos agropecuários, segundo o IBGE (2009b, 2009c). Mas antes de comentar os dados em si, é mister esclarecer alguns pontos sobre o que entende-se por plurirrendimentos e sua relação com a pluriatividade e o modo como foram classificadas as diversas receitas.

De fato, havendo pluriatividade também existem plurirrendimentos ou pelo menos pluri

Quadro 1. Classificação das fontes de receita dos estabelecimentos agropecuários

\begin{tabular}{|l|l|}
\hline \multirow{4}{*}{ Receitas Agropecuárias (RA) } & Receita de origem animal \\
\cline { 2 - 2 } & Receitas da produção vegetal \\
\cline { 2 - 2 } & Receitas de venda de animais criados em cativeiro \\
\cline { 2 - 2 } & Receitas de venda de húmus \\
\cline { 2 - 2 } & Receita de venda de esterco \\
\cline { 2 - 2 } & Receitas de venda de pescado \\
\hline Receitas de Aposentadorias e Transferências & Receitas de aposentadoria, pensão, etc. \\
\cline { 2 - 2 } & Receitas de programas sociais do Governo \\
\hline \multirow{3}{*}{ Receitas de Outras Fontes (ROT) } & Receitas de doações ou ajudas \\
\cline { 2 - 2 } & Receitas de desinvestimentos \\
\hline & Receitas de exploração mineral \\
\cline { 2 - 2 } & Receitas obtidas com a prestação de serviços a empresas integradoras \\
\cline { 2 - 2 } & Receitas de serviço de beneficiamento para terceiros \\
\hline \multirow{2}{*}{$\begin{array}{l}\text { Receitas de Atividades Não Agropecuárias } \\
\text { (RANA) }\end{array}$} & Receitas de atividades não agrícolas \\
\cline { 2 - 2 } & Receitas de outras atividades não agrícolas \\
\cline { 2 - 2 } & Salários obtidos em atividades fora do estabelecimento \\
\cline { 2 - 2 } & Receitas de atividade de turismo rural \\
\hline Receita Total & Somatório das receitas anteriores \\
\hline
\end{tabular}

Fonte: Censo Agropecuário 2006 ("tabulação especial” realizada pelo IBGE).

Elaboração: Projeto Ipea/PGDR 2010/2011. 
ou múltiplas fontes de ingresso. No entanto, as análises sobre as fontes de ingressos exigem alguns cuidados. Primeiro, há de se diferenciar os conceitos de renda e de receita. Renda se refere ao valor da remuneração dos fatores ou meios empregados na produção agropecuária. Portanto, para realizar o seu cálculo econômico é necessário deduzir do valor total da produção os custos de produção, a depreciação, os juros e amortizações, além de outros elementos. Receita, por sua vez, é uma noção essencialmente contábil, que refere-se à recebimentos líquidos na forma de ingressos monetários. É com este último conceito que o IBGE trabalha e que também utilizamos neste artigo. Obviamente, é possível calcular as rendas e seria muito interessante analisar o impacto da pluriatividade na composição das mesmas. Todavia, é muito complicado verificar empiricamente, ao menos na forma em que estão agregados os dados do CA2006, se há uma relação de causalidade direta entre os tipos de pluriatividade e as fontes de renda. Não é possível afirmar com exatidão que à cada fonte de renda corresponde uma atividade determinada. Por isso, o máximo que pode-se afirmar é que a pluriatividade contribui para a diversificação das fontes de renda, sem contudo poder mensurar a dimensão dessa contribuição, restringindo a análise às receitas.

As receitas obtidas pelos estabelecimentos agropecuários foram classificadas em cinco categorias distintas. As receitas agropecuárias (RA) incluem, além das ingressos provenientes da venda de produtos de origem animal e vegetal, as receitas provenientes da venda de outros produtos dos estabelecimentos que não entram diretamente nessa categoria (animais criados em cativeiro, húmus, esterco, pescado). Seria possível objetar que a inclusão das receitas de venda de pescado na receita agropecuária, por exemplo, é indevida, pois poderia estar relacionada à uma clássica atividade não agrícola, os chamados "pesque pagues". Mas como não há como apurar a procedência da venda (se pesque pague, sistema de integração, etc.), optou-se por incluí-la na receita agropecuária simplemente por ser o pescado, afinal de contas, um animal. As receitas provenientes da venda de produtos da agroindústria rural também estão incluídas nas receitas agropecuárias, de acordo com a origem do produto (animal ou vegetal). Isso não é o mais adequado, uma vez que essa fonte de receita corresponde à atividades pára agrícolas, características da pluriatividade agrária. Mesmo que se esteja sobreestimando as receitas agropecuárias, vale lembrar que, conforme a definição adotada neste trabalho e aceita pela maioria dos estudos, a pluriatividade é um fenômeno que pressupõem a combinação de pelo menos duas atividades, sendo uma delas a agricultura. Portanto, é plenamente legítimo incluir as rendas/receitas provenientes da atividade agropecuária entre os plurirrendimentos.

Há um conjunto de fontes de receita que não possui absolutamente nenhuma relação com as atividades produtivas, sejam elas agrícolas ou não agrícolas. O primeiro conjunto, denominado receitas de aposentadorias e transferências (RAT), inclui os ingressos monetários advindos de benefícios concedidos pelo governo e políticas redistributivas, composto por aposentadorias e pensões e por programas sociais de transferência de renda. O segundo conjunto, chamado receitas de outras fontes (ROF), inclui ingressos monetários cuja origem depende de relações de reciprocidade, no caso das receitas de doações ou ajudas, ou então de sacrifícios do próprio patrimônio, no caso dos desinvestimentos. Apesar de ambas as fontes (RAT e ROF) não poderem ser consideradas rendas, elas também não podem ser excluídas da análise da pluriatividade. Ellis (2000) é muito claro em mostrar que estratégias de diversificação das rendas e receitas são tão importantes quanto as de diversificação das atividades e ocupações, pois podem representar uma proteção às famílias em situações de risco, choques ou vulnerabilidades, tão freqüentes no meio rural, sobretudo nas regiões mais empobrecidas. À medida que as famílias conseguem ter um portfólio mais diversificado de meios de vida, com mais opções de trabalho e renda, tornando-se pluriativas, suas condições de vida tendem a melhorar, adqui- 
rindo maior estabilidade, e inclusive a sua produtividade pode aumentar.

Por fim, as duas últimas fontes de receita são as que possuem o tipo de relação mais clara e evidente com o exercício da pluriatividade e dispensam comentários. As outras receitas do trabalho (ORT) incluem ingressos advindos de pagamento por atividades ligadas a pluriatividade agrária (mineração, prestação de serviços, etc.). Enquanto as receitas de atividades não agropecuárias (RANA) advém daquelas atividades mais características da pluriatividade intersetorial (salários obtidos fora do estabelecimento e turismo rural, entre outras).

Para o Brasil como um todo (Figura 2), as receitas provenientes de atividades agropecu- árias constituem-se nas mais importantes fontes de ganhos na composição total das receitas, como seria esperado. Porém, há uma considerável variação nos percentuais entre AF e ANF e entre as unidades territoriais. A receita total da ANF excede em mais de duas vezes a da AF e a receita agrícola em mais de três vezes. Só que a ANF é mais dependente da receita agropecuária, já que esta representa $85,5 \%$ da receita total, enquanto que para a AF esse percentual é menor, $71,1 \%$ da receita total. Claro que pode-se objetar que, em termos absolutos, calculadas as médias de cada tipo de receita para o número de agricultores de cada categoria, algumas receitas, apesar de percentualmente pouco representativas para os estabelecimentos da ANF, mesmo assim seriam

Figura 2. Plurirrendimentos dos Estabelecimentos Pluriativos no Brasil, segundo a Agricultura Familiar e Agricultura Não Familiar
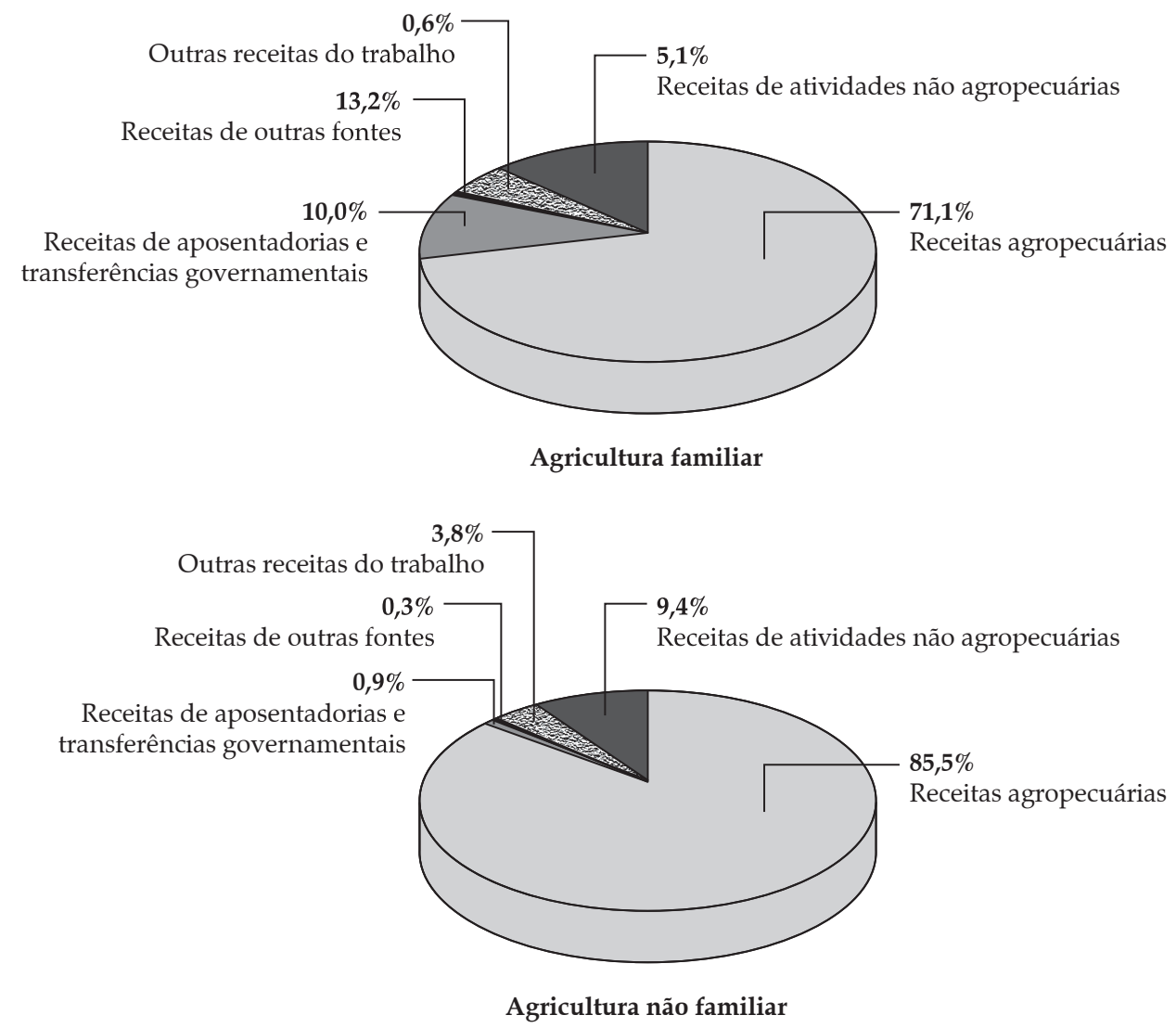

Fonte: Censo Agropecuário 2006 ("tabulação especial” realizada pelo IBGE).

Elaboração: Projeto Ipea/PGDR 2010/2011. 
Figura 3. Plurirrendimentos dos estabelecimentos Pluriativos na Região Sul, segundo a Agricultura Familiar e Agricultura Não Familiar

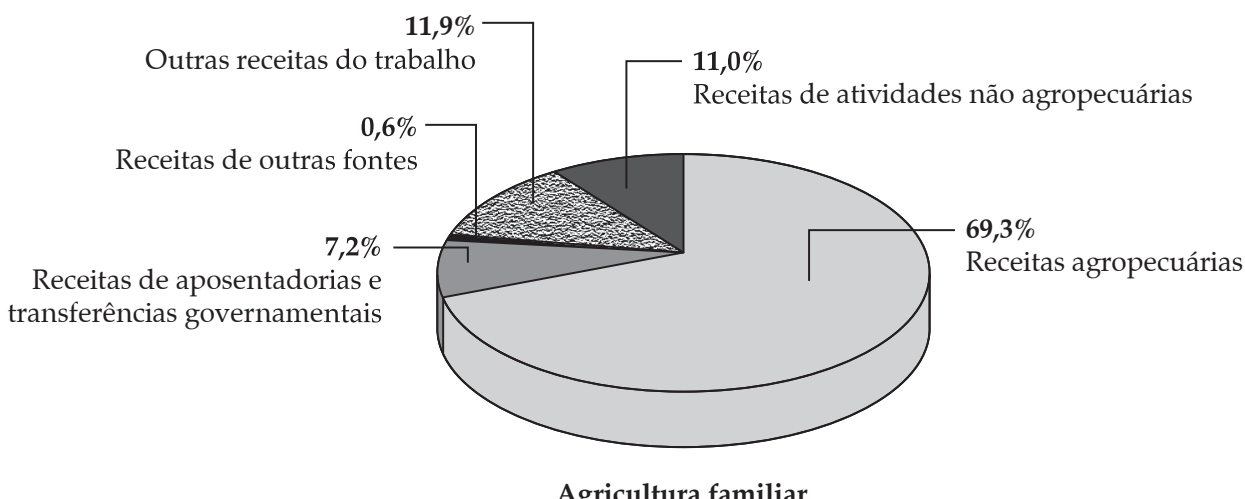

Agricultura familiar

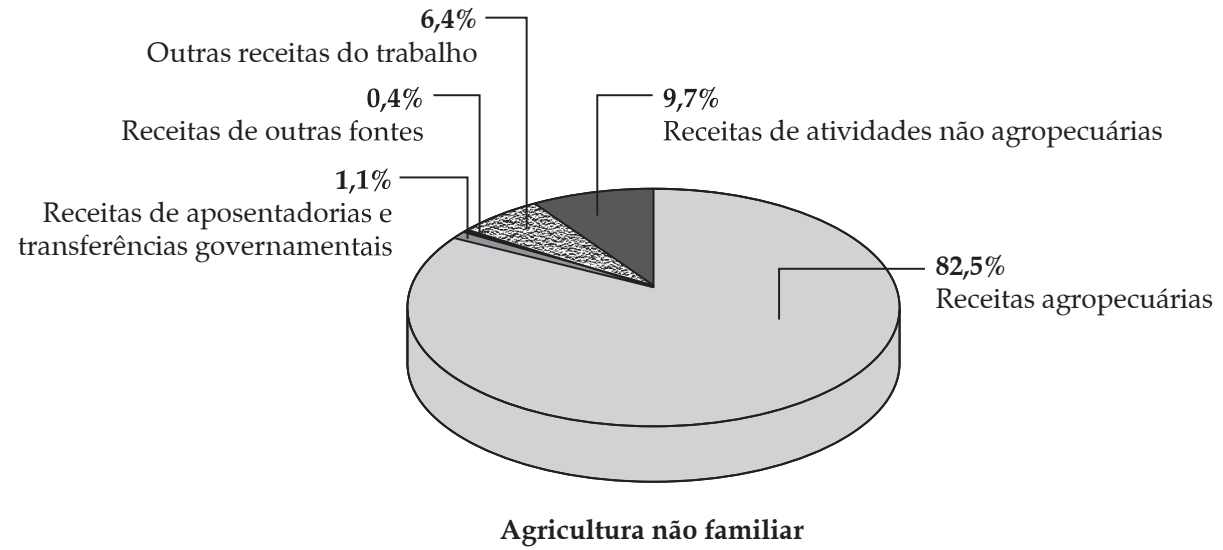

Fonte: Censo Agropecuário 2006 ("tabulação especial" realizada pelo IBGE).

Elaboração: Projeto Ipea/PGDR 2010/2011.

maiores do que para os da $\mathrm{AF}$, como é o caso das outras receitas do trabalho e, mais ainda, das receitas de atividades não agropecuárias.

Um aspecto que parece interessante reter diz respeito à significativa importância das receitas de atividades não agropecuárias e da enorme importância das receitas de aposentadorias e transferências governamentais para os estabelecimentos da $\mathrm{AF}$, em regra mais sujeitos a situações de pobreza e insegurança alimentar, como aquelas da Previdência Social Rural e do Programa Bolsa Família, respectivamente. ${ }^{16}$

16. Segundo dados do Censo Demográfico 2010, 13,4\% dos domicílios do Brasil encontram-se em situação de pobreza extrema (até $1 / 2$ salario mínimo per capita) e são potenciais beneficiários do Programa Bolsa Família. No meio urbano $5,4 \%$ da população se encontra nessa situação e no meio
Pesquisas já conseguiram apurar, por exemplo, que o programa de transferência condicionada (Bolsa Família) exerce um impacto positivo sobre o consumo de alimentos dessas famílias, pois $87 \%$ deste valor é utilizado para comprar alimentos (BENINI, SAMPAIO e SAMPAIO, 2008). E outras já demonstraram que o aumento na concessão de

rural o percentual chega a $25,5 \%$. A situação é pior no Nordeste e um pouco melhor noSul. No Nordeste $26,2 \%$ da população se encontra em condição de pobreza extrema, sendo que no meio urbano o percentual é de $11,7 \%$ e no meio rural chega a escandalosos $35,4 \%$. No Sul $5,75 \%$ da população é potencial beneficiário do Bolsa Família por encontrar-se em situação de pobreza extrema, sendo que no meio urbano o percentual é de $1,9 \%$ da população e no meio rural chega a $6,8 \%$. Ou seja, a pobreza extrema e, consequentemente, os potenciais beneficiários das transferências do Programa Bolsa Família, concentram-se especialmente no meio rural e na região Nordeste do país. 
aposentadorias para os agricultores tem impactado positivamente para a redução no número de domicílios com renda per capita média abaixo da linha de pobreza, para a relativa desconcentração da renda e para a melhoria nas condições de vida, como moradia e acesso a bens de consumo duráveis no meio rural (KATO e TARGÍNO, 2009).

Na região Sul (Figura 3) as receitas dos estabelecimentos pluriativos são ligeiramente mais diversificadas do que no Brasil como um todo. Isso implica que nesta região há uma menor dependência em relação às receitas agropecuárias, sobretudo na agricultura familiar. Outra característica do Sul é o peso um pouco menor das receitas de aposentadorias e transferências e um maior peso das outras receitas do trabalho na formação da receita total. Na agricultura familiar as outras receitas do trabalho chegam a figurar como a segunda maior, na frente mesmo das receitas de atividades não agropecuárias. Há também uma menor desigualdade entre as categorias AF e ANF na distribuição do valor absoluto dos rendimentos em relação ao que ocorre no país em geral, com exceção às receitas agropecuárias.

No Nordeste (Figura 4), por sua vez, o peso das receitas agropecuárias para a formação da receita total, apesar de predominante, é menor do que no Brasil e ainda menor em relação ao que ocorre na região Sul. Só que nesse caso a explicação não está no maior peso das outras receitas do trabalho, como no Sul, mas das receitas de atividades não agropecuárias no caso da $\operatorname{ANF}(13,5 \%)$ e nas

Figura 4. Plurirrendimentos dos estabelecimentos Pluriativos na Região Nordeste, segundo a Agricultura Familiar e Agricultura Não Familiar

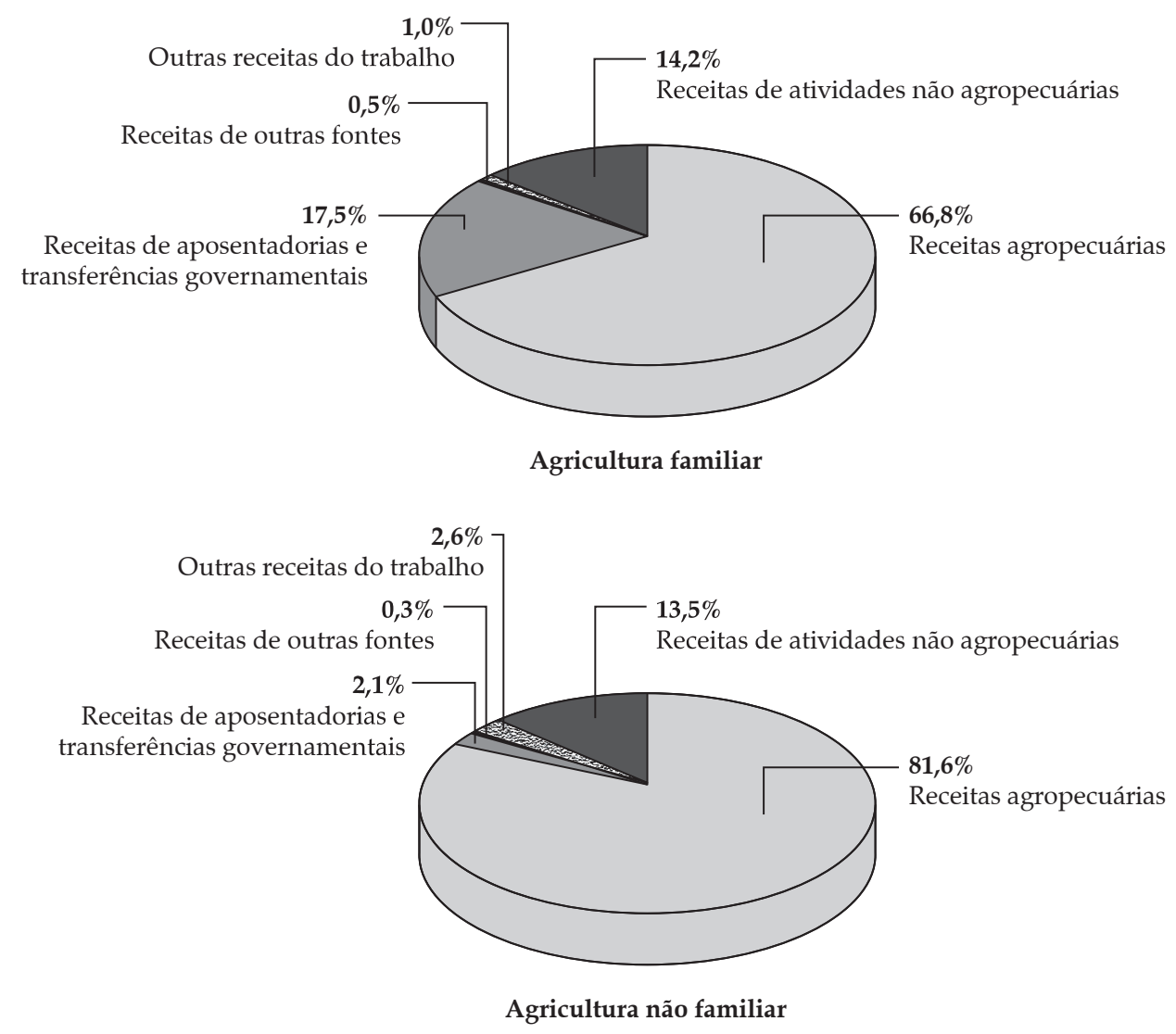

Fonte: Censo Agropecuário 2006 ("tabulação especial” realizada pelo IBGE).

Elaboração: Projeto Ipea/PGDR 2010/2011. 
receitas de atividades não agropecuárias (14,2\%) e, principalmente, nas receitas de aposentadorias e transferências governamentais $(17,5 \%)$ no caso da $\mathrm{AF}$, por ser ali onde se encontra a maior concentração de famílias consideradas "pobres" no Brasil, as beneficiárias mais aptas ao recebimento dos recursos do Programa Bolsa Família e também aquelas onde o recebimento dos recursos de aposentadoria assume uma grande importância.

Ao abordar os dados sobre os plurirrendimentos em termos percentuais e em uma perspectiva comparativa por unidade territorial, percebe-se que as receitas agropecuárias são predominantes em todas as regiões e para ambas as categorias, porém tem maior peso entre os agricultores não familiares, sendo que tanto na região Sul como na Nordeste esse tipo de receita fica abaixo do que para o Brasil. As receitas de aposentadorias, pensões e transferências governamentais são pouco significativas na formação da receita total dos estabelecimentos não familiares, ao contrário do que ocorre com os estabelecimentos familiares, sobretudo na região Nordeste, onde são muito significativas. Mas chama atenção o elevado percentual de estabelecimentos pluriativos da ANF (onde a incidência de pobreza deveria ser muito reduzida) que declararam recebimento de receitas provenientes de transferências governamentais (Programa Bolsa Família). As chamadas receitas de outras fontes (basicamente doações e ajudas), ao menos de acordo com o que foi declarado no CA 2006, são pouco representativas. Já a importância das outras receitas do trabalho variam bastante de região para região e de categoria para categoria, sendo mais importantes na região Sul e entre os agricultores familiares. E, por fim, as receitas de atividades não agropecuárias, assumem um grande peso na formação da receita total dos estabelecimentos, principalmente na região Nordeste.

\section{Considerações finais}

Neste trabalho procuramos identificar e caracterizar os 1.910.131 "estabelecimentos agropecuários pluriativos", que representam 37\% do total dos 5.175.489 estabelecimentos agropecuários brasileiros apurados pelo último Censo Agropecuário de 2006. Do total de estabelecimento pluriativos, $1.491 .080(78,1 \%)$ são classificados como de agricultura familiar (AF) e 419.051 (21,9\%) como de agricultura não familiar (ANF). Na região Sul, onde foram recenseados 1.006.181 estabelecimentos agropecuários (19,4\% do total do país), 355.185 (35,3\%) são pluriativos, sendo que destes $275.945(77,7 \%)$ são de AF e $79.240(22,3 \%)$ são de ANF. E na região Nordeste, dos 2.454.006 estabelecimentos agropecuários (47,41\% do total do país), 907.489 (37\%) são pluriativos, sendo que destes $752.040(82,9 \%)$ são de AF e $155.449(17,1 \%)$ são de ANF.

No que diz respeito aos plurirrendimentos, verificou-se que as receitas agropecuárias mantêm um peso menor da formação da receita total nos estabelecimentos de agricultura familiar vis-a-vis nos estabelecimentos de agricultura não familiar: respectivamente $71,1 \%$ contra $85,5 \%$ no Brasil, 69,3\% contra 82,5\% no Sul e 66,8\% contra $81,6 \%$ no Nordeste. Por outro lado, o peso das receitas de aposentadorias, pensões e transferências governamentais, é muito maior entre os agricultores familiares: $10 \%$ no Brasil, 7,2\% no Sul e $17,5 \%$ no Nordeste. No entanto, na região Sul as outras receitas do trabalho representam uma importância considerável na formação da receita total, especialmente para a agricultura familiar, para a qual representa 11,9\%. Na região Nordeste, por sua vez, as receitas de atividades não agropecuárias (especialmente salários recebidos fora do estabelecimento) possuem uma importância considerável, especialmente entre os não familiares.

Os estudos sobre pluriatividade e atividades não agrícolas desenvolveram de forma profícua desde a segunda metade da década de 1990, utilizando sobretudo dados secundários domiciliares gerados pelas PNADs, sendo o projeto Rurbano até hoje uma referência importante. No período mais recente este estudos com dados secundários receberam vigorosa contribuição de estudos qualitativos, muitos deles analisando casos específicos nas mais diversas áreas rurais do Brasil. Esta trajetória de estudos e pesquisas ganhou 
recentemente um significativo reforço a partir do último Censo Agropecuário, em que o IBGE passou a levantar dados censitários sobre as múltiplas inserções ocupacionais dos indivíduos e dos membros das famílias que formam os estabelecimentos agropecuários do Brasil. Neste sentido, vale ressaltar que o Censo Agropecuário tornou-se uma fonte importante não apenas da dinâmica produtiva da realidade agropecuária brasileira, mas também do perfil sociológico e econômico dos agricultores e suas famílias e do espaço rural e suas relações com o espaço urbano.

Todavia, a nova senda de estudos aberta sobre a pluriatividade dos estabelecimentos agropecuários ainda tem uma longa agenda de estudos e pesquisas pela frente, entre as quais destaca-se que a primeira questão a ser pesquisada com maior profundidade está relacionada à identificação das razões que explicam a incidência pluriatividade nos estabelecimentos de agricultura não familiar. Na medida em que a maioria dos estudos sobre o tema sempre se preocupou quase que estritamente com a agricultura familiar e, ainda mais, em regiões onde ela é absolutamente predominante, como em várias regióes do Rio Grande do Sul, o Oeste de Santa Catarina e o Sudoeste e Oeste do Paraná, ainda não existem explicações fundamentadas, seja teóricas e/ou empíricas, para a pluriatividade na agricultura denominada "patronal". $\mathrm{O}$ aprendizado que obtivemos com a realização deste trabalho indica que talvez o primeiro passo para esclarecer a natureza deste fenômeno seria cruzar as informações sobre os estabelecimentos pluriativos com a questão cinco do questionário do CA 2006, onde se pergunta "qual é o local de residência da pessoa que dirige o estabelecimento?" O segundo passo poderia ser cruzar as informações sobre a pluriatividade com variáveis como "condição do produtor em relação às terras" (proprietário; assentado sem titulação definitiva; arrendatário; parceiro; e ocupante) e, principalmente, com as variáveis de "condição legal do produtor" (produtor individual; condomínio, consórcio ou sociedade de pessoas; cooperativa; sociedade anônima S/A ou sociedade limitada LTDA.; instituição de utilidade pública; e governo).
A segunda questão da agenda de investigações vindouras, que está intimamente vinculada e decorre da primeira, é que persistem dúvidas quanto à adequação da classificação de alguns dos estabelecimentos como agricultura não familiar, imaginando-se que de fato poderiam pertencer à agricultura familiar, possivelmente por conta de problemas com a própria metodologia do IBGE, baseada nos critérios da Lei 11.326. Entre as razões que suscitaram essa dúvida destaca-se a existência de um percentual considerável de estabelecimentos não familiares que recebem Bolsa Família (11,8\% no Brasil; 5,5\% no Sul; e $23,4 \%$ no Nordeste). Qual o motivo de tantos estabelecimentos patronais ou empresariais receberem transferências do referido programa? Seriam os parceiros e trabalhadores residentes em domićlios dentro dos estabelecimentos que recebem o benefício ou seriam os produtores e membros da família considerados "pobres"? No entanto, haveria principalmente um problema intrínseco à própria pluriatividade. Como até junho de 2011 os estabelecimentos que tinham mais da metade da sua renda proveniente de atividades econômicas não vinculadas ao próprio estabelecimento não poderiam ser considerados de agricultura familiar pelos critérios da Lei 11.326, que orienta a metodologia do IBGE, muitos agricultores familiares pluriativos, que consequentemente possuem a maior parte dos seus rendimentos não vinculados a atividades agropecuárias dentro do estabelecimento, possivelmente acabaram sendo classificados como agricultores não familiares. Identificar e mensurar este universo e incluí-lo na análise da pluriatividade é tarefa extremamente importante, além de ser também urgente, pois pode vir a contribuir no sentido de aumentar a abrangência do programa e de ajudar a qualificar e trazer melhorias para as próprias políticas públicas para a agricultura e o meio rural.

Entre os entraves do Pronaf - principal política pública para a agricultura familiar no Brasil - está o problema da pluriatividade entre os critérios de classificação do seu público alvo, que até a pouco previam que parcela majoritária da renda das unidades fosse oriunda exclusiva- 
mente de atividades agrícolas, especialmente nos antigos grupos D e E. Além disso, a formatação atual do programa ainda não oferece condições apropriadas ao estímulo da pluriatividade, fundamentalmente porque os apoios praticamente restringem-se à concessão de créditos (exemplo do Pronaf agroindústria e turismo rural). Malgrado os avanços nos anos recentes, ainda não foram desenvolvidas ações mais abrangentes de capacitação e esclarecimento aos extensionistas rurais. Outro ponto refere-se à linha de crédito para investimento, em que a ampla parcela dos recursos e contratos é destinada às atividades agrícolas, notadamente a máquinas e equipamentos, que induzem o agricultor a fazer "mais do mesmo".

Deste modo, não obstante sua indiscutível contribuição para a agricultura familiar no Brasil, o Pronaf ainda não combina instrumentos de estímulo às atividades agrícolas com outros que fortaleçam as atividades não agrícolas e a pluriatividade, que antes de representar um simples processo de proletarização rural, representam um processo mais amplo e complexo de mercantilização e diversificação da agricultura familiar. Vale chamar a atenção para a necessidade de reflexão sobre o destino do Pronaf e suas possíveis alterações. Se a crítica ao seu viés excessivamente agrícola não lhe retira muitos dos seus méritos, ela não o exime da necessidade de enriquecê-lo com a implementação de outros tipos de políticas complementares, que possam estimular a pluriatividade e seus efeitos positivos sobre a diversificação das fontes de renda das famílias agricultoras de modo mais abrangente.

\section{Referências bibliográficas}

ANJOS, F. S. Agricultura familiar em transformação: os colonos-operários de Massaranduba (SC). Pelotas: UFPEL, 1995.

Agricultura familiar, pluriatividade e desenvolvimento rural no Sul do Brasil. Pelotas: EGUFPEL, 2003.

ANJOS, F. S. e CALDAS, N. V. Pluriactivity and family farming in Brazil: the case of Rio Grande do Sul. Cepal Review, Santiago, v. 93, 2007, p. 149-164.
ARKLERTON TRUST (Research) Ltd. Adaptation des ménages agricoles en Europe Occidentale 1987-1991. Comisión Européene, de. 1992. (Rapport final du Programme de Recherche sur les Structures et la Pluriactivité des Menajes Agricoles).

BANCO INTERNACIONAL DE RECONSTRUÇÃO E DESENVOLVIMENTO; BANCO MUNDIAL. Relatório sobre o desenvolvimento mundial de 2008: Agricultura para o Desenvolvimento. Washington, DC: BIRD/ BM, 2008. Disponível em: <www.fao.org/sd/erp/ workshopafrica2007/WDR08_overview_port.pdf $>$. Acesso em: 21 de maio de 2010.

BAZOTTI, A., NAZARENO, L. R. e CINTRA, A. P. U. Um ensaio sobre as famílias agrícolas paranaenses a partir das PNADs 1992, 1998, 2005 e 2007. Revista Paranaense de Desenvolvimento, Curitiba, n. 117, 2009, p. 123-145.

BENINI, G., SAMPAIO, B. e SAMPAIO, Y. S. B. Impactos do programa Bolsa Família sobre os gastos com alimentos de famílias rurais. Revista da $A B E T$, São Paulo, v. 7, n. 1, 2008, p. 5-19.

BRUN, A. e FULLER, A. Farm family pluriactivity in Western Europe. United Kingdom: The Arkleton Research, 1991.

CAMPANHOLA, C. e GRAZIANO DA SILVA, J. (Orgs.). O novo rural brasileiro: novas ruralidades e urbanização. Brasília, DF: Embrapa/UNICAMP, 2004.

CARNEIRO, M. J. Pluriatividade no campo: o caso francês. Revista Brasileira de Ciências Sociais, São Paulo, n. 11, v. 32, 1996, p. 89-105.

Do rural e do urbano: uma nova terminologia para uma velha dicotomia ou a reemergência da ruralidade? In: II Seminário sobre o Novo Rural Brasileiro. Campinas - IE/Unicamp, outubro de 2001.

Camponeses, agricultores e pluriatividade. Rio de Janeiro: Contracapa, 1998.

CONTERATO, M. A. Dinâmicas regionais de desenvolvimento rural e estilos de agricultura: uma análise a partir do Rio Grande do Sul. Tese (Doutorado em Desenvolvimento Rural) - Programa de PósGraduação em Desenvolvimento Rural, Faculdade de Ciências Econômicas, Universidade Federal do Rio Grande do Sul. Porto Alegre, 2008.

ESCHER, F. Os assaltos do moinho satânico nos campos $e$ os contramovimentos da Agricultura Familiar: atores sociais, instituições e desenvolvimento rural no Sudoeste do Paraná. Dissertação (Mestrado em Desenvolvimento Rural) - Programa de Pós-graduação em Desenvolvimento Rural, Faculdade de Ciências 
Econômicas, Universidade Federal do Rio Grande do Sul. Porto Alegre, 2011.

FULLER, A. M. From part-time farming to pluriactivity: a decade of change in rural Europe. Journal of rural Studies, London, v. 6, n. 4, p. 361-373, 1990.

GRAZIANO DA SILVA, J. O novo rural brasileiro. Campinas, UNICAMP, Instituto de Economia, (Coleção Pesquisas, 1), 1999.

GUANZIROLI, C. E., BUAINAIN, A. M. e DI SABBATTO, A. Dez anos de evolução da agricultura familiar no Brasil: (1996 e 2006). Revista de Economia e Sociologia Rural, Piracicaba, v. 50, n. 2, 2012, p. 351-370.

HERÉDIA, B., PALMEIRA, M. e LEITE, S. Sociedade e economia do "agronegócio" no Brasil. Revista Brasileira de Ciências Sociais, São Paulo, v. 25, n. 74, 2010, p. 159-176.

INSTITUTO BRASILEIRO DE GEOGRAFIA E ESTATÍSTICA - IBGE. Notas Técnicas. Censo Agropecuário 2006. Rio de Janeiro: IBGE, 2009a. $2009 \mathrm{~b}$.

Censo Agropecuário 2006. Rio de Janeiro: IBGE, . Censo Agropecuário 2006: Agricultura Familiar. Rio de Janeiro: IBGE, 2009c.

KAGEYAMA, A. Pluriatividade e ruralidade: aspectos metodológicos. Economia Aplicada, São Paulo, v. 2, n. 3, 1998 , p. $515-551$.

KAGEYAMA, A. A., BERGAMASCO, S. M. P. P. e OLIVEIRA, J. T. A. Uma tipologia dos estabelecimentos agropecuários do Brasil a partir do Censo de 2006. Revista de Economia e Sociologia Rural, Piracicaba, v. 51, n. 1,2013 , p. $105-122$.

KATO, R. e TARGINO, I. Previdência social e pobreza na zona rural do Nordeste brasileiro (1991-2000). Revista da ABET, v. 8, n. 1, 2009, p. 7-23.

LAURENTI, A. C., TELLES, T. S. e PELLINI, T. Evolução da ocupação e do rendimento das pessoas na nova ruralidade do Brasil no período 2001 a 2009. In: Anais do 51 Congresso da Sociedade Brasileira de Economia, Administração e Sociologia Rural, Belém - PA, 21 a 24 de julho de 2013.

LIMA, J. R. e NEDER, H. D. Efeitos da pluriatividade e rendas não-agrícolas sobre a pobreza e desigualdade rural na região Nordeste. In: Anais do 47 Congresso da Sociedade Brasileira de Economia, Administração e Sociologia Rural, Porto Alegre-RS, 26 a 30 de Julho de 2009.

MATTEI, L. A relevância da família como unidade de análise nos estudos sobre pluriatividade. Revista de Economia Rural, Rio de Janeiro, v. 45, n. 4, 2007, p. $1055-1073$.
NASCIMENTO, C. A. e CARDOZO, S. A. Redes urbanas regionais e a pluriatividade das famílias rurais no Nordeste e no Sul do Brasil, 1992-1999 e 2001-2005. Revista Econômica do Nordeste, Fortaleza, v. 38, n. 4, out./ dez. 2007, p. 637-658.

NASCIMENTO, C. A., OLIVEIRA, R. B., SOUTO, I. J. G. e MENDES, S. R. A qualidade do emprego rural na região Nordeste (2002 e 2005). Revista da ABET, São Paulo, v. 7, n. 2, 2008, p. 76-95.

NASCIMENTO, C. A. e AQUINO, J. R. Ocupação e renda das famílias rurais do Rio Grande do Norte no início do século XXI (2002-2008). Economia Política do Desenvolvimento, Maceió, v. 3, n. 8, 2010, p. 7-27.

NEVES, D. P. Agricultura familiar: questões metodológicas. Revista Reforma Agrária, Campinas/SP, n. 25, mai/dez. 1995, p. 21-37.

- Agricultura Familiar e mercado de trabalho. Revista Estudos Sociedade e Agricultura, Rio de Janeiro, n. 8, abr. 1997, p. 7-25.

PERONDI, M. A. Diversificação dos meios de vida $e$ mercantilização da agricultura familiar. Tese (Doutorado em Desenvolvimento Rural) - Programa de PósGraduação em Desenvolvimento Rural, Faculdade de Ciências Econômicas, Universidade Federal do Rio Grande do Sul. Porto Alegre, 2007.

PLOEG, J. D. van der. Camponeses e impérios alimentares: lutas por autonomia e sustentabilidade na era da globalização. Porto Alegre: Editora da UFRGS, 2008.

SAKAMOTO, C. S. e MAIA, A. G. Dinâmica do mercado de trabalho agrícola e impactos sobre a distribuição dos rendimentos nos anos 2000. Revista da ABET, São Paulo, v. 11, n. 2, 2012, p. 11-31.

SCHNEIDER, S. O desenvolvimento agrícola e as transformações da estrutura agrária nos países do capitalismo avançado: a pluriatividade. Revista Reforma Agrária, Campinas/SP, n. 24, v. 3, set/dez. 1994, p. 106-132. . Agricultura familiar e industrialização. 2. ed. Porto Alegre: Editora da UFRGS, 1999.

A pluriatividade na agricultura familiar. 2. ed. Porto Alegre: Editora da UFRGS, 2003.

A importância da pluriatividade para as políticas públicas no Brasil. Revista de Política Agrícola, Brasília, a. 16, n. 3, jul/set. 2007, p. 15-34.

A pluriatividade no meio rural brasileiro: características e perspectivas de investigação. In: GRAMMONT, H.C. de; MARTINEZ VALLE, L. (Org.). La pluriactividad en el campo latinoamericano. 1. ed. Quito/ 
Equador: Editora Flacso - Serie FORO, 2009, v. 1, p. 132-161.

SCHNEIDER, S., CONTERATO, M. A., SOUZA, M., ESCHER, F., SCARTON, L. M. e RUCKERT, L. Pluriatividade e plurirrendimentos nos estabelecimentos agropecuários do Brasil e das regiões Sul e Nordeste: uma análise a partir do Censo Agropecuário 2006. Brasília: IPEA, 2013. (Relatório de Pesquisa).

SCHURMAN, M. L., PAULI, R. I. P., NASCIMENTO, C. A. e SANTOS, R. G. As ocupações e rendas das famílias rurais gaúchas no período 1992-1999 e 2001-2008. In: Anais do 48 Congresso da Sociedade Brasileira de Economia, Administração e Sociologia Rural, Campo Grande-MS, de 25 a 28 de Julho de 2010.

SEYFERTH, G. A Colonização Alemã no Vale do Itajaí-Mirim: um estudo de desenvolvimento econômico. Porto Alegre: Movimento, 1974. (Coleção Documentos Brasileiros)

Camponeses ou operários? O significado da categoria colono numa situação de mudança. Revista do Museu Paulista, São Paulo, v. 29, Nova Série, 1984.

Aspectos da proletarização do campesinato no Vale do Itajaí (SC): os colonos-operários. In: LOPES,
J. S. L. (Org.). Cultura e identidade operária: aspectos da cultura da classe trabalhadora. São Paulo: Marco Zero, 1987.

SOUZA, M. e NASCIMENTO, C. A. Evolução das ocupações e comparação das rendas das famílias rurais no Estado do Rio Grande do Sul: 2001-2004. In: Encontro de Economia Gaúcha, 3., 2006, Porto Alegre. Anais... Porto Alegre: PUCRS, 2006.

VEIGA, J. E. Cidades Imaginárias: o Brasil é menos urbano do que se calcula. Campinas: Tores Associados, 2002.

WANDERLEY, M. N. B. Olhares sobre o "rural" brasileiro. Revista Raízes, Campina Grande, v. 23, n. 1-2, jan/dez. 2004.

WORLD BANK. Rural development: from vision to action. Executive Summary. Washington: WORLD BANK, 1997. (Environmental and Socially Sustainable Development Studies and Monograph Series, n. 12).

- The rural non-farm economy: report on presentations and discussions at the World Bank, n.1517. Washington: WORLD BANK, 2000. 
